\title{
CARACTERIZACIÓN Y CLASIFICACIÓN DE ALGUNOS ULTISOLES DE LA REGIÓN DE LOS SANTOS, TALAMANCA, COSTA RICA ${ }^{1}$
}

\author{
Miguel Chinchilla ${ }^{2 / *}$, Rafael Mata**, Alfredo Alvarado ${ }^{* *}$ \\ Palabras clave: Clasificación suelos, Ultisoles, Los Santos, Talamanca. \\ Keywords: Soil classification, Ultisols, Los Santos, Talamanca.
}

Recibido: 03/06/10

\section{RESUMEN}

Se caracterizaron y clasificaron 26 suelos del orden de los Ultisoles en la parte media de la subcuenca del río Pirrís. Los suelos se desarrollan en relieves ondulados a fuertemente ondulados, a partir de materiales del Pleistoceno al Oligoceno y de origen: 1) sedimentario marino, 2) volcánico andesítico-basáltico y 3) coluvial, bajo una vegetación natural de bosque muy húmedo a húmedo y un régimen de humedad ústico. Los suelos son profundos, tienen horizonte argílico, texturas finas a muy finas, reacción ácida a fuertemente ácida y pueden poseer un horizonte con concreciones de manganeso, asociadas a los antiguos niveles de agua de la cuenca del río Pirrís y un material geológico rico en este elemento. El contenido de arcilla, la CIC, la densidad aparente y real varían con el material parental, mientras que el contenido de bases y la fijación de fósforo son indiferentes de la litología sobre el que se desarrollan. Por taxonomía se reconocieron 2 subórdenes: Humults y Ustults. Cinco grandes grupos: Haplustults, Paleustults, Haplohumults, Palehumults, Rhodustults. Nueve subgrupos: Typic Haplustults, Aquic Haplustults, Typic Paleustults, Andic Haplohumults, Aquic Haplohumults, Aquandic Haplohumults, Ustic

1 Este trabajo forma parte de la tesis de maestría del primer autor.

2 Autor para correspondencia. Correo electrónico: mchinchillaa@ice.go.cr
Aceptado: 15/03/11 
Haplohumults, Andic Palehumults, Typic Rhodustults. Los subgrupos Andic y Aquandic exhiben, en los horizontes superficiales, deposiciones de cenizas volcánicas de una edad cercana a los 700 años. Los subsuelos arcillosos encontrados en Ultisoles de Talamanca, son mucho más antiguos que su horizonte suprayacente y su formación data de 9000 a 65000 años.

\section{INTRODUCCIÓN}

En la Cordillera de Talamanca, solevantada durante el Mioceno Superior y todo el Plioceno (Bergoing 2007), se ha reportado la existencia de Ultisoles, Entisoles, Andisoles, Espodosoles, Inceptisoles e Histosoles (Macias 1969, Harris 1971 a, b, Holdridge et al. 1971, Martini y Macías 1974, Otárola y Alvarado 1977, López 1978, Landaeta 1977, Landaeta et al. 1978, Alvarado et al. 1982, Sancho y Núñez 1985, Blaser y Camacho 1991, van Uffelen 1991, Solórzano 1997, ICAFECIA 2000, Kappelle y van Uffelen 2005, Gómez y Chinchilla 2005, Winowiecki 2008). La mayoría de estos suelos se forman por pérdida de sílice y bases de cenizas volcánicas (Andisoles), la acumulación de arcilla con óxidos de $\mathrm{Fe}$ y $\mathrm{Al}$ a través de la latolización (Ultisoles) y en menor cuantía por la translocación al horizonte $\mathrm{B}$ de óxidos de Fe y Al (Espodosoles y Placudands) o la acumulación de materia orgánica sobre la superficie y entre los intersticios de la rocas (Histosoles).

Los Ultisoles representan el $21 \%$ del territorio costarricense (Mata 1991), se forman con alta temperatura ambiente, sobre casi cualquier material parental, con la precipitación superando la evapotranspiración y un movimiento vertical de agua a través del perfil de suelo que permite lixiviación de bases ( $\mathrm{Na}, \mathrm{K}, \mathrm{Ca} \mathrm{Mg}$ ), remoción de sílice y acumulación de hierro y aluminio (Wilding et al. 1983). Su principal característica es la formación de un horizonte argílico con
Haplohumults, Aquandic Haplohumults, Ustic Haplohumults, Andic Palehumults, Typic Rhodustults. The Andic and Aquandic subgroups exhibit, in superficial horizons, depositions of volcanic ash materials dated around 700 years of age. Buried clayey subsoils of Talamanca Ultisols are much older than their over laying horizon, being dated as old as 9000 to 65000 years of age.

bajo contenido de bases y acumulación de arcilla iluviada (Soil Survey Staff 2006). El color de estos suelos se debe básicamente al grado de hidratación del Fe con tonalidades pardo rojizo o rojizo en su estado oxidado y pardo amarillento y amarillento en su forma hidratada.

En la Cordillera de Talamanca, los Ultisoles se encuentran principalmente en laderas empinadas de la parte alta y media de la cordillera y sobre terrazas antiguas de los ríos que la drenan (Macías 1969, Kesel y Spicer 1985, Mata y Ramírez 1999, Cubero 2002, Gómez y Chinchilla 2005, Driese et al. 2007, Pelt et al. 2008, Winowiechi 2008).

Driese et al. (2007) indican la presencia de horizontes arcillosos y ácidos (Btb), en áreas de suelos formados sobre cenizas volcánicas de Talamanca, producto de la pérdida de bases y sílice en este ambiente húmedo y frío. Cuando el grado evolutivo de los suelos es mayor, aunque se hayan formado a partir de cenizas volcánicas o cuando la ceniza volcánica se ha erosionado, los suelos se clasifican como Humic Hapludults o Ultic Haplustalfs (Mata y Ramírez 1999).

El objetivo general del presente trabajo fue ampliar la información de los Ultisoles modales en la subcuenca del río Pirrís. Los objetivos específicos definidos inicialmente son: 1) Cartografiar los Ultisoles situados aguas arriba del sitio de presa; 2) Describir sus perfiles modales desde el punto de vista morfológico, físico y químico; 
3) Clasificarlos por taxonomía y 4) Elaborar un mapa de Ultisoles a nivel de semidetalle.

\section{MATERIALES Y MÉTODOS}

Los materiales y métodos utilizados en el trabajo de Ultisoles fueron incluidos y descritos con detalle en el artículo de Chinchilla et al. (2011). En general el trabajo campo en la subcuenca incluyo 421 observaciones con barreno, 30 observaciones en microcalicatas y se realizó la apertura de 53 calicatas, de las cuales 19 fueron costeadas por el ICE. La descripción y muestreo de las calicatas se hizo de acuerdo con el USDANRCS (2002). La clasificación de los suelos en órdenes, subórdenes, grandes grupos, subgrupos y familia se realizó con los lineamientos del Soil Survey Staff (2006). El cartografiado general y las áreas se realizaron con el Sistema de Información Geográfica Arc-View, versión 3.3. Para el cartografiado y clasificación de Ultisoles en la región de los Santos se utilizaron 26 perfiles: 9 fueron descritos por el ICE (2006), 10 por Sancho y Nuñez (1985) y 7 por el ICAFÉ-CIA (2000).

\section{RESULTADOS Y DISCUSIÓN}

A continuación se presentan y discuten los resultados más relevantes de los Ultisoles de la región bajo estudio. Para mayor detalle, se refiere al lector a la tesis de maestría del primer autor, disponible en la biblioteca de la Universidad de Costa Rica.

1. Generalidades: Los Ultisoles ocupan la mayor extensión de terreno en el nivel medio de la subcuenca. Se han desarrollado en laderas de origen tectónico erosivo (pendientes 30 y $60 \%$ ) de la Cordillera de Talamanca y de la Fila Brunqueña y sobre terrazas antiguas (pendientes de 15 a $30 \%$ ) relacionadas con el levantamiento tectónico de Talamanca, compartiendo áreas menores con suelos de los órdenes de los Inceptisoles y Entisoles que también están ubicados en laderas de las formaciones Grifo Alto y Térraba. Los Ultisoles tienen una génesis sobre 3 litologías de edad diferente: sedimentaria de origen marino (lutitas $\mathrm{y}$ areniscas de grano fino y medio) y edad Oligoceno a Mioceno Inferior (34 a 23 Ma); volcánica (lavas basálticas, andesíticas a andesítica basáltica y rocas piroclásticas) del Plioceno (5,5 -1,9 Ma) y coluvial del Pleistoceno con edad entre 11000 años y 1,8 Ma (ICE 2007). La cobertura vegetal natural se incluye en 3 zonas de vida, a saber el Bosque Muy Húmedo Montano Bajo (bmh-MB), el Bosque Muy Húmedo Premontano (bmh-P) y el Bosque Húmedo Montano Bajo (bh-MB) y un uso actual de café. La precipitación muestra un período seco y otro lluvioso. Los suelos reportados en la literatura para esta unidad incluyen los siguientes subgrupos: Typic, Ustic y Orthoxic Tropohumults, Typic, Ustic y Ustoxic Humitropepts, Ustic y Oxic Dystropepts, Typic Ustropepts (Sancho y Núñez 1982), Andic Haplohumults y Humic Hapludults (ICAFE-CIA 2000).

Las características más importantes para el diagnóstico de los Ultisoles son la presencia de un horizonte argílico o de un horizonte cándico, acompañado por una saturación de bases (por suma de cationes) inferior a 35\% a una profundidad de $125 \mathrm{~cm}$ por debajo del límite superior del horizonte argílico o cándico o hasta una profundidad de $180 \mathrm{~cm}$ desde la superficie del suelo (Soil Survey Staff 2006). Una amplia variedad de materiales parentales permiten su formación ya que pueden desarrollarse a partir de materiales bajos en bases y minerales de alteración con suficiente arcilla para formar un horizonte argílico, o bien a partir de materiales parentales con alto contenido de minerales meteorizables (Wilding et al. 1983). El proceso pedogenético más importante en la formación de los Ultisoles es la migración de arcilla desde la parte superficial hasta el horizonte iluvial Bt (Soil Survey Staff 2006), además de meteorización y lavado de bases, desilicación, formación de arcillas, acumulación de sesquióxidos, desarrollo de color de suelo y melanización por adición o pérdida de materia orgánica. La mayoría de los Ultisoles se forman a partir materiales de parentales del Pleistoceno o más antiguas (Wilding et al. 1983). La edad de suelos desarrollados al sur de Costa 
Rica, sobre los abanicos aluviales de pie de monte de la Cordillera de Talamanca (900-1000 msnm.), fue estimada con ${ }^{14} \mathrm{C}$ en 45000 años, mientras que los más antiguos tienen más de 65000 años (Kesel y Spicer 1985). Criterios de humedad del perfil y contenido de materia orgánica permiten subdividir a los Ultisoles en 5 subórdenes (Boul et al. 1989).

2. Clasificación: En la cuenca media del río Pirrís los 27 perfiles de Ultisoles se agruparon en 2 subórdenes: 1) Humults, suborden más abundante y que presenta acumulaciones importantes de materia orgánica y 2) Ustults, definidos por el largo período seco de su régimen de humedad. A nivel de grandes grupos se encontraron Haplustults, Paleustults, Haplohumults y Palehumults, diferenciables entre sí por el contenido de arcilla en profundidad y los Rhodustults por lo brillante y puro de su color rojo (Keys to Soil Taxonomy 2006). La ubicación de Ultisoles en el área de estudio, se presenta en la Figura 1, en la cual se nota la dominancia de los Humults y los Ustults.

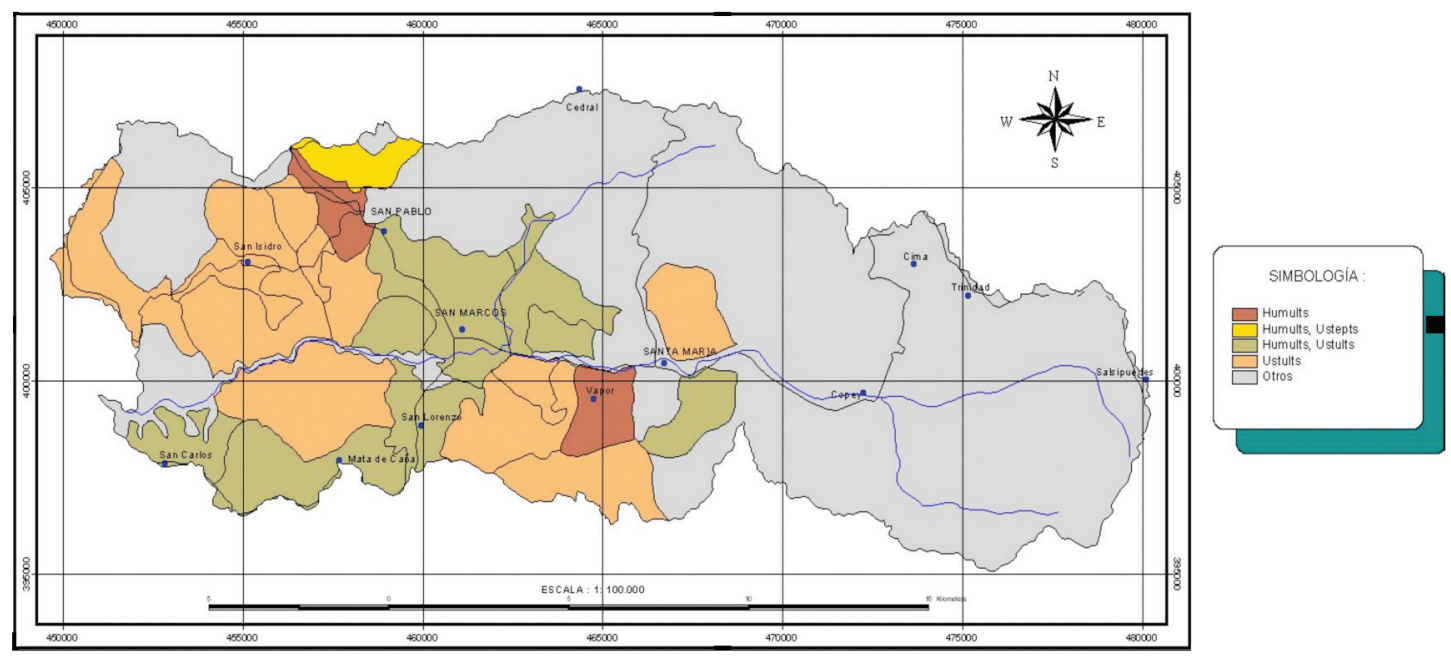

Fig. 1. Ubicación de Ultisoles en la Subcuenca del río Pirrís.

3. Morfología: Los Ultisoles estudiados son profundos a muy profundos, con secuencia de horizontes $\mathrm{A} / \mathrm{Bt}, \mathrm{A} / \mathrm{Bt} / \mathrm{BC}, \mathrm{A} / \mathrm{Bt} / \mathrm{BC} / \mathrm{C}$ y A/Bt/C. El proceso de iluviación es evidente al observarse revestimientos arcillosos (cutanes) localizados en las superficies de los peds del horizonte Bt. En la parte inferior del horizonte $\mathrm{Bt}$, en algunos suelos se observa una movilización de Fe en diferente estado de hidratación, expresada como manchas rojas y amarillas. En los materiales coluviales se encontró horizontes $\mathrm{B}$ con concreciones $(\mathrm{Bc})$ ó nódulos de Mn, posiblemente asociados con paleo niveles del río Pirrís, o de aguas subterráneas en un material geológico alto en este elemento. El horizonte A es comúnmente menor a $30 \mathrm{~cm}$, con matiz 10 YR a 7,5 YR, value entre 3 y 4 y croma de 1 a 4 . Cuando se presenta un horizonte $A B$, este tiene espesores entre 9 y $26 \mathrm{~cm}$, matiz 10 YR-7,5 YR-5 YR, value de 3 a 4 y croma de 3 a 6. El horizonte Bt se puede subdividir en Bt1, $\mathrm{Bt} 2, \mathrm{Bt} 2, \mathrm{Bt} 4$, que alcanzan espesores de 13 a 128 $\mathrm{cm}$, de matiz predominante 7,5YR-5YR-2,5YR, valor 4 a 6 y croma de 4 a 8 . El color pardo de los horizontes superficiales tiene relación con el contenido de material orgánica y los rojos-amarillos en el subsuelo con los contenidos de óxidos de hierro en diferente estado de hidratación (Cuadro 1 y Figura 2). 
Cuadro 1. Características morfológicas de suelos desarrollados sobre superficies antiguas. (Continúa).

\begin{tabular}{|c|c|c|c|c|}
\hline Material parental & $\begin{array}{l}\text { Clasificación } \\
\text { taxonómica }\end{array}$ & Horizonte & $\begin{array}{l}(\mathrm{cm}) \\
\text { prof. }\end{array}$ & Color munsell \\
\hline \multirow{21}{*}{$\begin{array}{l}\frac{\pi}{2} \\
\text { 苟 }\end{array}$} & Kanhaplic & $\mathrm{A}$ & $0-29$ & 7,5 YR 4/4 \\
\hline & Haplustults & Bt1 & $29-56$ & 7,5 YR 4/6 \\
\hline & 23 & Bt2 & $56-147$ & 5 YR 4/6 \\
\hline & & $\mathrm{C}$ & $147-200$ & $5 \mathrm{YR} 4 / 6$ \\
\hline & Typic "Aquic" & $\mathrm{A}$ & $0-30$ & 7,5 YR 4/4 \\
\hline & Paleustults & Bt1 & $30-140$ & 7,5 YR 5/6 \\
\hline & 21 & Bt2 & $140-180$ & 5 YR 5/8 \\
\hline & Aquic & Ap & $0-12$ & 7,5 YR $3 / 4$ \\
\hline & Palehumults & $\mathrm{AB}$ & $12-38$ & $7,5 \mathrm{YR} 4 / 4$ \\
\hline & 42 & Bt1 & $38-166$ & $5 \mathrm{YR} 4 / 6$ \\
\hline & Aquandic & Ap & $0-20$ & $10 \mathrm{YR} 3 / 3$ \\
\hline & Haplohumults & $\mathrm{A} 2$ & $20-28$ & $7,5 \mathrm{YR} 4 / 6$ \\
\hline & 43 & $\mathrm{Bc}$ & $28-44$ & $7,5 \mathrm{YR} 4 / 6$ \\
\hline & & Bt1 & $44-65$ & $5 \mathrm{YR} 5 / 8$ \\
\hline & & $\mathrm{BC}$ & $65-81$ & $2,5 \mathrm{YR} 4 / 8$ \\
\hline & & $\mathrm{C}$ & $81-150$ & $2,5 \mathrm{YR} 4 / 8$ \\
\hline & Aquic & Ap & $0-15$ & $10 \mathrm{YR} 3 / 4$ \\
\hline & Haplohumults & $\mathrm{AB}$ & $15-27$ & $10 \mathrm{YR} 4 / 3$ \\
\hline & 45 & Bt1 & $27-63$ & 7,5 YR 5/6 \\
\hline & & Bt2 & $63-105$ & 10 YR $6 / 8 ; 2,5$ YR 5/8 \\
\hline & & $\mathrm{BC}$ & $105-145$ & 10 YR 6/8 \\
\hline \multirow{17}{*}{ 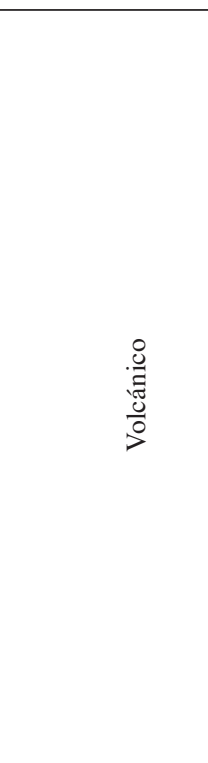 } & Andic & Ap & $0-21$ & 10YR 3/1 \\
\hline & Palehumults & Bt1 & $21-45$ & 7,5 YR 4/6 \\
\hline & 4 & Bt2 & $45-69$ & 5 YR 5/6 \\
\hline & & $\mathrm{Bt} 3$ & $69-150$ & 5 YR 5/8 \\
\hline & Andic & Ap & $0-17$ & $10 \mathrm{YR} 2 / 1$ \\
\hline & Palehumults & $\mathrm{AB}$ & $17-26$ & $10 \mathrm{YR} 3 / 3$ \\
\hline & 50 & Bt1 & $26-50$ & $10 \mathrm{YR} 4 / 4$ \\
\hline & & Bt2 & $50-100$ & 10YR 5/6 \\
\hline & & Bt3 & $100-150$ & $10 \mathrm{YR} 5 / 8$ \\
\hline & Andic & Ap & $0-30$ & $10 \mathrm{YR} 2 / 2$ \\
\hline & Haplohumults & Bt1 & $30-75$ & 5 YR 4/6 \\
\hline & 5 & Bt2 & $75-110$ & $2,5 \mathrm{YR} 4 / 6$ \\
\hline & & Bt3 & $110-150$ & $10 \mathrm{YR} 4 / 8$ \\
\hline & Aquic & $\mathrm{A}$ & $0-20$ & $10 \mathrm{YR} 4 / 4$ \\
\hline & Haplohumults & Bt1 & $20-32$ & $10 \mathrm{YR} 5 / 6$ \\
\hline & 13 & Bt2 & $32-128$ & 10 YR 6/8 \\
\hline & & $\mathrm{C}$ & $128-205$ & 10 YR 6/8 \\
\hline
\end{tabular}


Cuadro 1. Características morfológicas de suelos desarrollados sobre superficies antiguas. (Continúa).

\begin{tabular}{|c|c|c|c|c|}
\hline Material parental & Clasificación & Horizonte & $(\mathrm{cm})$ & Color munsell \\
\hline \multirow{21}{*}{$\begin{array}{l}\frac{0}{0} \\
\frac{\pi}{0} \\
\frac{\pi}{0}\end{array}$} & Aquandic & A & $0-20$ & 7,5 YR 3/2 \\
\hline & Haplohumults & Bt1 & $20-40$ & 10 YR 5/6 \\
\hline & \multirow[t]{2}{*}{22} & $\mathrm{Bg} 2$ & $40-67$ & 10 YR 4/2; 7,5 YR 5/6 \\
\hline & & $\mathrm{C} 1$ & $67-x x$ & 7,5 YR 5/6 \\
\hline & Typic & Ap & $0-11$ & $10 \mathrm{YR} 4 / 4$ \\
\hline & Haplustults & Bt1 & $11-25$ & 5 YR 5/8 \\
\hline & \multirow[t]{3}{*}{9} & Bt2 & $25-73$ & 2,5 YR 5/8 \\
\hline & & $\mathrm{BC}$ & $73-105$ & $2,5 \mathrm{YR} 4 / 8$ \\
\hline & & $\mathrm{C}$ & $105-150$ & 2,5 YR 5/8 \\
\hline & Typic & Ap & $0-19$ & 10YR 3/6 \\
\hline & \multirow{3}{*}{10} & Bt1 & $19-56$ & $5 \mathrm{YR} 4 / 4$ \\
\hline & & Bt2 & $56-93$ & $5 \mathrm{YR} 4 / 4$ \\
\hline & & $\mathrm{BC}$ & $93-150$ & 10 YR 6/8 \\
\hline & Typic & Ap & $0-20$ & 7,5 YR 5/6 \\
\hline & Haplustults & Bt1 & $20-50$ & 5 YR 5/8 \\
\hline & 19 & $\mathrm{Bt} 2$ & $50-145$ & 7,5 YR 5/8 \\
\hline & Typic & Ap & $0-8$ & 7,5 YR $2,5 / 3$ \\
\hline & Paleustults & $\mathrm{AB}$ & $8-24$ & 7,5 YR 4/6 \\
\hline & \multirow[t]{3}{*}{39} & Bt1 & $24-70$ & $2,5 \mathrm{YR} 4 / 8$ \\
\hline & & Bt2 & $70-115$ & $2,5 \mathrm{YR} 4 / 6$ \\
\hline & & $\mathrm{Bt} 3$ & $115-155$ & $2,5 \mathrm{YR} 4 / 6$ \\
\hline \multirow{15}{*}{ 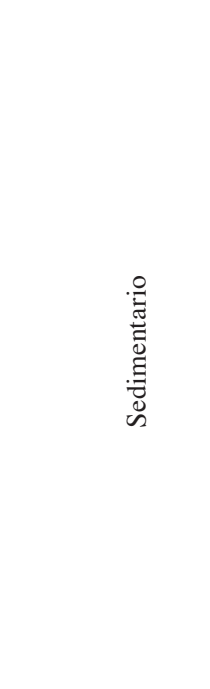 } & Andic & Ap & $0-11$ & $10 \mathrm{YR} 6 / 6$ \\
\hline & Haplohumults & Bt1 & $11-24$ & $2,5 \mathrm{YR} 3 / 6$ \\
\hline & \multirow[t]{3}{*}{1} & Bt2 & $24-54$ & 2,5 YR 4/6 \\
\hline & & $\mathrm{Bt} 3$ & $54-108$ & 2,5 YR 5/6 \\
\hline & & Bt4 & $108-150$ & 2,5 YR $3 / 8$ \\
\hline & Andic & Ap & $0-23$ & $10 \mathrm{YR} 2 / 1$ \\
\hline & Haplohumults & Bt1 & $23-61$ & 5 YR 3/4 \\
\hline & \multirow[t]{2}{*}{6} & Bt2 & $61-87$ & 7,5 YR 4/6 \\
\hline & & $\mathrm{BC}$ & $87-150$ & 7,5 YR 5/6 \\
\hline & Andic & Ap & $0-13$ & 10 YR 3/4 \\
\hline & Haplohumults & $\mathrm{AB}$ & $13-25$ & 7,5 YR 4/4 \\
\hline & \multirow[t]{4}{*}{44} & Bt1 & $25-57$ & 7,5 YR 5/8 \\
\hline & & $\mathrm{Bt} 2$ & $57-104$ & 7,5 YR 6/8 \\
\hline & & Bt3 & $104-130$ & 5 YR 5/8 \\
\hline & & $\mathrm{BC}$ & $130-145$ & 7,5 YR 5,5/8 \\
\hline
\end{tabular}


Cuadro 1. Características morfológicas de suelos desarrollados sobre superficies antiguas.

\begin{tabular}{|c|c|c|c|c|}
\hline Material parental & $\begin{array}{l}\text { Clasificación } \\
\text { taxonómica }\end{array}$ & Horizonte & (cm) Prof. & Color munsell \\
\hline \multirow{38}{*}{ 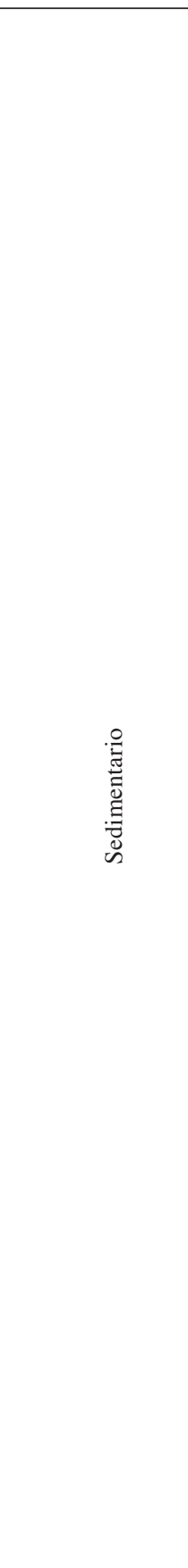 } & Ustic & $\mathrm{A}$ & $0-17$ & $5 \mathrm{YR} 3 / 3$ \\
\hline & Haplohumults & Bt1 & $17-40$ & $5 \mathrm{YR} 4 / 6$ \\
\hline & \multirow[t]{2}{*}{12} & Bt2 & $40-130$ & $2,5 \mathrm{YR} 4 / 6$ \\
\hline & & $\mathrm{Bt} 3$ & $130-200$ & $5 \mathrm{YR} 4 / 6$ \\
\hline & Andic & Ap & $0-18$ & $10 \mathrm{YR} 2 / 2$ \\
\hline & Palehumults & $\mathrm{AB}$ & $18-28$ & $10 \mathrm{YR} 3 / 3$ \\
\hline & \multirow[t]{3}{*}{38} & Btc1 & $28-46$ & $7,5 \mathrm{YR} 4 / 6$ \\
\hline & & Bt2 & $46-90$ & 5 YR 5/6 \\
\hline & & Bt3 & $90-120$ & $5 \mathrm{YR} 5 / 8$ \\
\hline & Andic & $\mathrm{A}$ & $0-22$ & $7,5 \mathrm{YR} 4 / 4$ \\
\hline & Palehumults & Bt1 & $22-45$ & 7,5 YR 5/6 \\
\hline & \multirow[t]{3}{*}{27} & Bt2 & $45-98$ & 5 YR 5/8 \\
\hline & & Bt3 & $98-170$ & $2,5 \mathrm{YR} 5 / 8$ \\
\hline & & $\mathrm{C}$ & $170-x x$ & $2,5 \mathrm{YR} 5 / 6$ \\
\hline & Ustic & $\mathrm{A}$ & $0-20$ & $5 \mathrm{YR} 3 / 4$ \\
\hline & Palehumults & Bt1 & $20-45$ & $5 \mathrm{YR} 4 / 6$ \\
\hline & \multirow[t]{2}{*}{26} & Bt2 & $45-165$ & $2,5 \mathrm{YR} 4 / 8$ \\
\hline & & $\mathrm{BC}$ & $165-\mathrm{xx}$ & 5 YR 5/8 \\
\hline & Aquic & A & $0-26$ & $10 \mathrm{YR} 4 / 4$ \\
\hline & \multirow[t]{2}{*}{ Palehumults } & Bt1 & $26-65$ & 7,5 YR 5/6 \\
\hline & & Bt2 & $65-185$ & $2,5 \mathrm{YR} 4 / 8$ \\
\hline & Typic & Ap & $0-23$ & $10 \mathrm{YR} 3 / 3$ \\
\hline & Haplustults & Bt1 & $23-59$ & $10 \mathrm{YR} 3 / 6$ \\
\hline & \multirow[t]{2}{*}{8} & Bt2 & $59-95$ & 10 YR 6/8 \\
\hline & & $\mathrm{BC}$ & $95-150$ & \\
\hline & Aquic & Ap & $0-15$ & $10 \mathrm{YR} 3 / 3$ \\
\hline & Haplustults & Bt1 & $15-45$ & $10 \mathrm{YR} 4 / 6$ \\
\hline & \multirow[t]{3}{*}{40} & Bt2 & $45-66$ & 10 YR 5/6 \\
\hline & & Bt3 & $66-123$ & 5 YR $5 / 8$ \\
\hline & & $\mathrm{BC}$ & $123-180$ & $5 \mathrm{YR} 5 / 8$ \\
\hline & Typic & Ap & $0-10$ & 7,5 YR 3/4 \\
\hline & Rhodustults & $\mathrm{AB}$ & $10-20$ & $5 \mathrm{YR} 4 / 6$ \\
\hline & \multirow[t]{2}{*}{41} & Bt1 & $20-70$ & $2,5 \mathrm{YR} 3 / 8$ \\
\hline & & $\mathrm{BC}$ & $70-150$ & 10 YR 7/6 \\
\hline & Andic & $\mathrm{A}$ & $0-42$ & 7,5 YR 4/4 \\
\hline & Palehumults & Bt1 & $42-64$ & 7,5 YR 5/6 \\
\hline & \multirow[t]{2}{*}{25} & Bt2 & $64-100$ & $5 \mathrm{YR} 4 / 6$ \\
\hline & & Bt3 & $100-160$ & $5 \mathrm{YR} 5 / 8$ \\
\hline
\end{tabular}



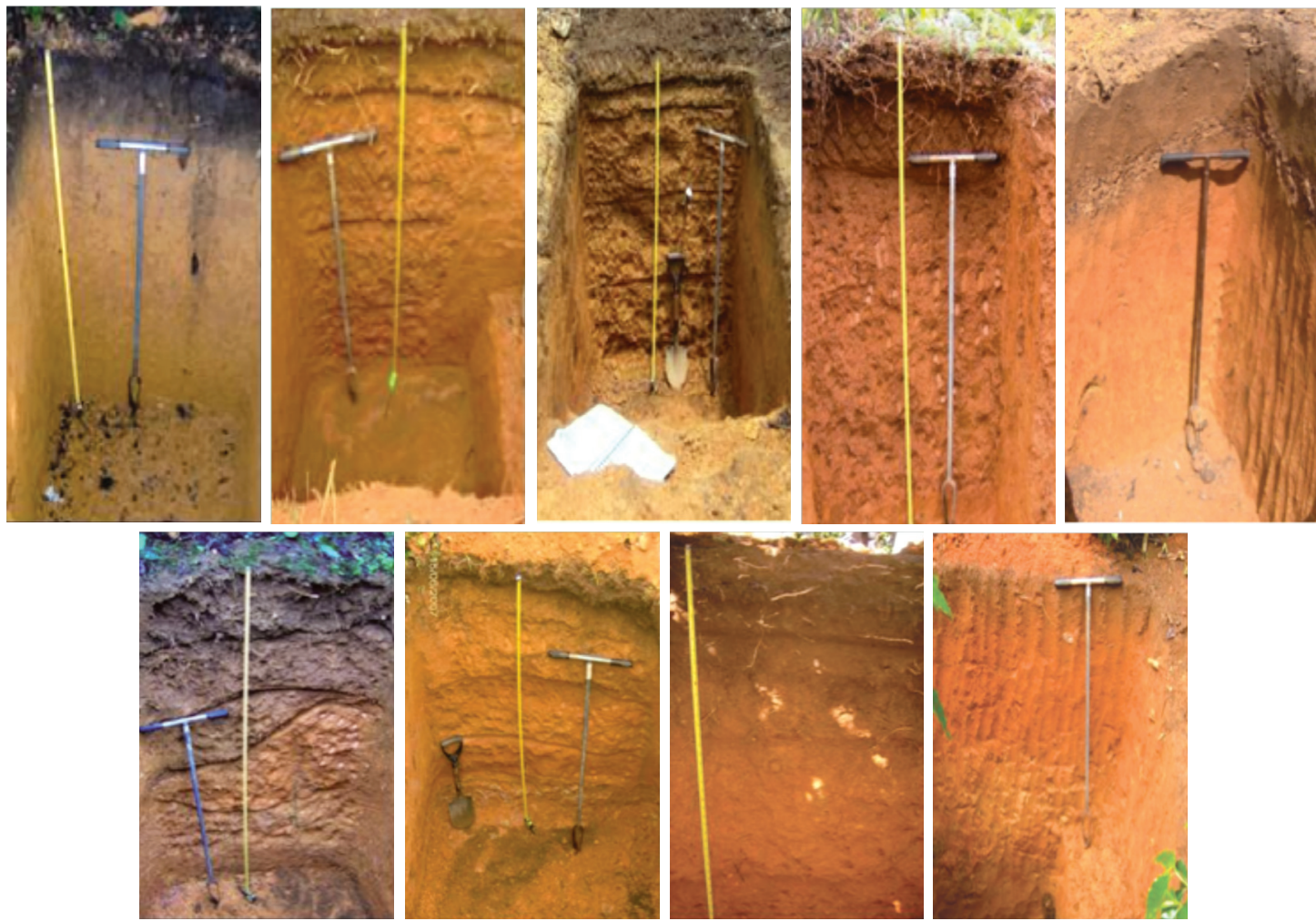

Fig. 2. Suelos sobre materiales volcánicos terciarios (a) Perfil 50, Andic Palehumults (b) Perfil 39, Typic Paleustults. Suelos sobre materiales coluviales antiguos (c) Perfil 45, Aquic Haplohumults. (d) Perfil 42, Aquic Palehumults (e) Perfil, Aquandic Haplohumults. Suelos sobre materiales sedimentarios terciarios (f) Perfil 40, Aquic Haplustults (g) Perfil 44, Andic Haplohumults. (h) Perfil 38, Andic Palehumults. (i) Perfil 41, Typic Rhodustults.

4. Distribución del tamaño de partículas: El contenido de arcilla se incrementa desde el horizonte A hacia el horizonte $\mathrm{B}$, para luego decrecer con la profundidad hasta el horizonte C. En general, el horizonte $\mathrm{A}$ es de textura arcillosa (promedio $35-45 \%$ de arcilla, máximo $71 \%$ y mínimo $12 \%)$. El poco contenido de arcilla en algunos horizontes A se asocia con el material

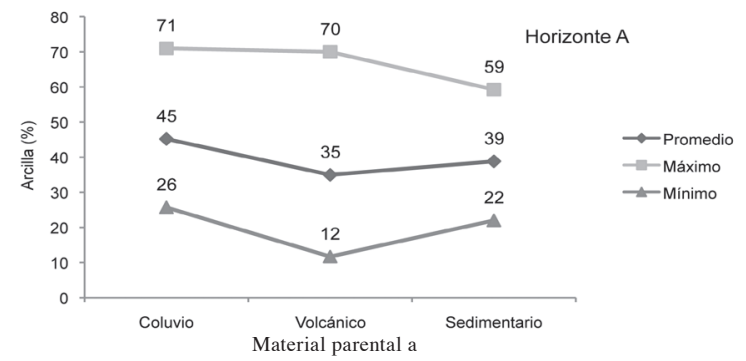

parental de origen volcánico (cenizas) depositado en la superficie de los suelos y que es de textura gruesa. Pocos horizontes A tienen contenidos de arcilla mayor a $60 \%$. El horizonte Bt es de textura fina a muy fina, más de $60 \%$ de arcilla, con un máximo de $80 \%$ y mínimos de $35 \%$ (Figura 3 y Cuadro 2).

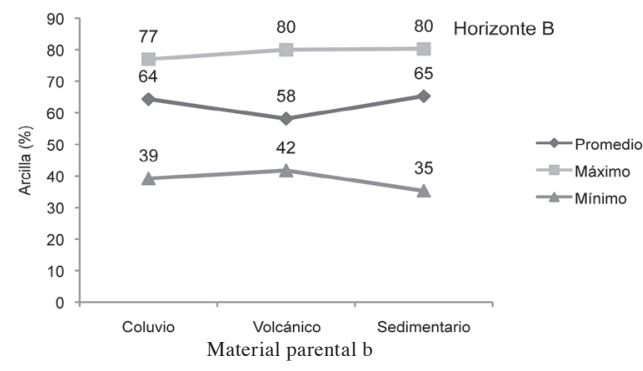

Fig. 3. Porcentaje de arcilla en el horizonte A (a) y horizonte Bt (b) de Ultisoles desarrollados sobre diferentes superficies geológicas. 
Cuadro 2. Características físicas de suelos desarrollados sobre superficies antiguas. (Continúa).

\begin{tabular}{|c|c|c|c|c|c|c|c|c|c|c|}
\hline \multirow{2}{*}{$\begin{array}{l}\text { Material } \\
\text { parental }\end{array}$} & \multirow{2}{*}{$\begin{array}{c}\text { Clasificación } \\
\text { taxonómica }\end{array}$} & \multirow[t]{2}{*}{ Horizonte } & \multirow[t]{2}{*}{ Prof. (cm) } & \multicolumn{3}{|c|}{ Textura $(\%)$} & \multirow{2}{*}{$\begin{array}{l}\text { Clase } \\
\text { textural }\end{array}$} & \multirow{2}{*}{$\begin{array}{l}\text { Mg. } \mathrm{m}^{-3} \\
\text { D. aparente }\end{array}$} & \multirow{2}{*}{$\begin{array}{l}\mathrm{Mg} \cdot \mathrm{m}^{-3} \\
\text { D. real }\end{array}$} & \multirow[t]{2}{*}{$\%$} \\
\hline & & & & Arena & Limo & Arcilla & & & & \\
\hline \multirow{21}{*}{$\frac{\bar{J}}{3}$} & Kanhaplic & A & $0-29$ & 16 & 24 & 60 & A & nd & 2,27 & nd \\
\hline & Haplustults & Bt1 & $29-56$ & 9 & 17 & 74 & A & nd & 2,72 & nd \\
\hline & 23 & Bt2 & $56-147$ & 9 & 38 & 53 & $\mathrm{~A}$ & nd & 2,43 & nd \\
\hline & & $\mathrm{C}$ & $147-200$ & 7 & 37 & 56 & $\mathrm{~A}$ & nd & 2,39 & nd \\
\hline & Typic "Aquic" & A & $0-30$ & 12 & 17 & 71 & A & nd & 2,12 & nd \\
\hline & Paleustults & Bt1 & $30-140$ & 6 & 17 & 77 & A & nd & 2,30 & nd \\
\hline & 21 & Bt2 & $140-180$ & 15 & 10 & 75 & A & nd & 2,30 & nd \\
\hline & Aquic & Ap & $0-12$ & 40 & 18 & 42 & $\mathrm{~A}$ & 1,32 & 2,70 & 51 \\
\hline & Palehumults & $\mathrm{AB}$ & $12-38$ & 32 & 17 & 51 & A & 1,02 & 2,70 & 62 \\
\hline & 42 & Bt1 & $38-166$ & 23 & 17 & 61 & A & 0,84 & 2,90 & 71 \\
\hline & & Ap & $0-20$ & 47 & 28 & 26 & FA a & 1,00 & 2,50 & 60 \\
\hline & Aquandic & A2 & $20-28$ & 44 & 18 & 38 & FA & 1,10 & 2,65 & 59 \\
\hline & Haplohumults & $\mathrm{Bc}$ & $28-44$ & 41 & 20 & 39 & FA & 1,26 & 2,80 & 55 \\
\hline & 43 & Bt1 & $44-65$ & 13 & 15 & 72 & A & 1,32 & 2,80 & 53 \\
\hline & & $\mathrm{BC}$ & $65-81$ & 21 & 15 & 64 & A & 1,22 & 2,80 & 56 \\
\hline & & $\mathrm{C}$ & $81-150$ & 31 & 13 & 57 & A & 1,17 & 2,70 & 57 \\
\hline & & Ap & $0-15$ & 51 & 20 & 29 & FA a & 0,90 & 2,61 & 66 \\
\hline & Aquic & $\mathrm{AB}$ & $15-27$ & 26 & 20 & 54 & A & 1,04 & 2,87 & 64 \\
\hline & Haplohumults & Bt1 & $27-63$ & 31 & 20 & 49 & A & 1,26 & 2,69 & 53 \\
\hline & 45 & Bt2 & $63-105$ & 24 & 20 & 57 & A & 1,23 & 2,78 & 56 \\
\hline & & $\mathrm{BC}$ & $105-145$ & 29 & 17 & 54 & $\mathrm{~A}$ & 1,15 & 2,90 & 60 \\
\hline \multirow{16}{*}{ 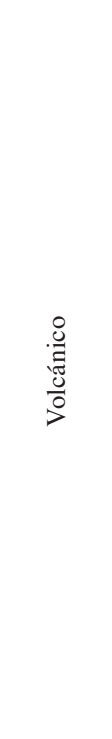 } & Andic & Ap & $0-21$ & 26 & 23 & 51 & A & 0,91 & 2,10 & 57 \\
\hline & Palehumults & Bt1 & $21-45$ & 18 & 14 & 69 & A & 0,95 & 2,34 & 59 \\
\hline & 4 & Bt2 & $45-69$ & 28 & 6 & 66 & A & 0,95 & 2,37 & 60 \\
\hline & & Bt3 & $69-150$ & 29 & 6 & 66 & A & 1,10 & 2,24 & 51 \\
\hline & Andic & Ap & $0-17$ & 49 & 40 & 12 & $\mathrm{~F}$ & 0,62 & 2,30 & 73 \\
\hline & Palehumults & $\mathrm{AB}$ & $17-26$ & 40 & 18 & 43 & A & 0,95 & 2,70 & 65 \\
\hline & 50 & Bt1 & $26-50$ & 20 & 18 & 62 & A & 1,16 & 2,80 & 59 \\
\hline & & Bt2 & $50-100$ & 23 & 13 & 64 & A & 1,09 & 2,70 & 60 \\
\hline & Andic & Ap & $0-30$ & 36 & 23 & 41 & A & 0,94 & 2,10 & 55 \\
\hline & Haplohumults & Bt1 & $30-75$ & 18 & 15 & 67 & A & 0,99 & 2,31 & 57 \\
\hline & 5 & Bt2 & $75-110$ & 13 & 13 & 74 & A & 1,07 & 2,42 & 56 \\
\hline & & Bt3 & $110-150$ & 35 & 23 & 42 & A & 1,35 & 2,44 & 45 \\
\hline & Aquic & A & $0-20$ & 56 & 30 & 14 & $\mathrm{Fa}$ & nd & 2,33 & nd \\
\hline & Haplohumults & Bt1 & $20-32$ & 26 & 30 & 44 & A & nd & 2,29 & nd \\
\hline & 13 & Bt2 & $32-128$ & 14 & 19 & 67 & A & nd & 2,45 & nd \\
\hline & & $\mathrm{C}$ & $128-205$ & 12 & 27 & 61 & A & nd & 2,65 & nd \\
\hline
\end{tabular}


Cuadro 2. Características físicas de suelos desarrollados sobre superficies antiguas (Continúa).

\begin{tabular}{|c|c|c|c|c|c|c|c|c|c|c|}
\hline \multirow{2}{*}{$\begin{array}{l}\text { Material } \\
\text { parental }\end{array}$} & \multirow{2}{*}{$\begin{array}{l}\text { Clasificación } \\
\text { taxonómica }\end{array}$} & \multirow[t]{2}{*}{ Horizonte } & \multirow[t]{2}{*}{ Prof. $(\mathrm{cm})$} & \multicolumn{3}{|c|}{ Textura (\%) } & \multirow{2}{*}{$\begin{array}{l}\text { Clase } \\
\text { textural }\end{array}$} & \multirow{2}{*}{$\begin{array}{l}\mathrm{Mg} \cdot \mathrm{m}^{-3} \\
\text { D. aparente }\end{array}$} & \multirow{2}{*}{$\begin{array}{l}\mathrm{Mg} \cdot \mathrm{m}^{-3} \\
\text { D. real }\end{array}$} & \multirow{2}{*}{$\%$} \\
\hline & & & & Arena & Limo & Arcilla & & & & \\
\hline \multirow{21}{*}{ 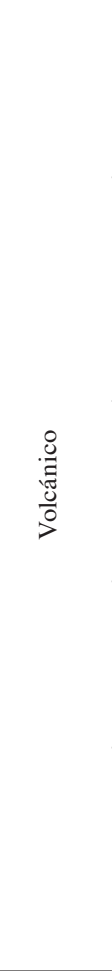 } & Aquandic & A & $0-20$ & 37 & 36 & 27 & FA & nd & 2,05 & nd \\
\hline & Haplohumults & Bt1 & $20-40$ & 19 & 34 & 47 & A & nd & 2,10 & nd \\
\hline & 22 & $\mathrm{Bg} 2$ & $40-67$ & 9 & 24 & 67 & A & nd & 2,63 & nd \\
\hline & & $\mathrm{C} 1$ & $67-x x$ & nd & nd & nd & nd & nd & nd & nd \\
\hline & Typic & Ap & $0-11$ & 44 & 29 & 28 & FA & 0,99 & 2,39 & 59 \\
\hline & Haplustults & Bt1 & $11-25$ & 23 & 29 & 48 & A & 1,09 & 2,45 & 56 \\
\hline & 9 & Bt2 & $25-73$ & 18 & 24 & 58 & A & 1,12 & 2,48 & 55 \\
\hline & & $\mathrm{BC}$ & $73-105$ & 35 & 21 & 44 & A & 1,13 & 2,46 & 54 \\
\hline & & $\mathrm{C}$ & $105-150$ & 51 & 29 & 20 & $\mathrm{~F}$ & 1,11 & 2,46 & 55 \\
\hline & Typic & Ap & $0-19$ & 23 & 37 & 40 & A & 0,99 & 2,33 & 58 \\
\hline & Haplustults & Bt1 & $19-56$ & 18 & 34 & 48 & A & 1,26 & 2,52 & 50 \\
\hline & 10 & $\mathrm{Bt} 2$ & $56-93$ & 25 & 32 & 43 & A & 1,21 & 2,60 & 53 \\
\hline & & $\mathrm{BC}$ & $93-150$ & 15 & 43 & 42 & AL & 1,07 & 2,51 & 57 \\
\hline & $\begin{array}{l}\text { Typic } \\
\text { Haplustults }\end{array}$ & Ap & $0-20$ & 8 & 22 & 70 & A & nd & 2,11 & nd \\
\hline & Haplustults & Bt1 & $20-50$ & 5 & 15 & 80 & A & nd & 2,27 & nd \\
\hline & 19 & Bt2 & $50-145$ & 4 & 35 & 69 & A & nd & 2,25 & nd \\
\hline & Typic & Ap & $0-8$ & 56 & 22 & 22 & FA a & 0,89 & 2,50 & 64 \\
\hline & Paleustults & $\mathrm{AB}$ & $8-24$ & 49 & 142 & 37 & $\mathrm{Aa}$ & 0,88 & 2,50 & 65 \\
\hline & 39 & Bt1 & $24-70$ & 31 & 12 & 57 & A & 1,04 & 2,56 & 59 \\
\hline & & Bt2 & $70-115$ & 32 & 12 & 56 & A & 1,15 & 2,73 & 58 \\
\hline & & Bt3 & $115-155$ & 29 & 14 & 57 & A & nd & 2,80 & nd \\
\hline \multirow{19}{*}{ 点 } & Andic & Ap & $0-11$ & 42 & 23 & 35 & FA & 1,06 & 2,27 & 53 \\
\hline & Haplohumults & Bt1 & $11-24$ & 11 & 19 & 70 & A & 0,93 & 2,37 & 61 \\
\hline & 1 & $\mathrm{Bt} 2$ & $24-54$ & 3 & 20 & 77 & A & 1,24 & 2,58 & 52 \\
\hline & & Bt3 & $54-108$ & 7 & 25 & 68 & A & 1,28 & 2,52 & 49 \\
\hline & & Bt4 & $108-150$ & 29 & 27 & 44 & A & 1,28 & 2,60 & 51 \\
\hline & Andic & Ap & $0-23$ & 43 & 34 & 23 & $\mathrm{~F}$ & 0,74 & 2,24 & 67 \\
\hline & Haplohumults & Bt1 & $23-61$ & 12 & 28 & 60 & A & 0,92 & 2,52 & 63 \\
\hline & 6 & $\mathrm{Bt} 2$ & $61-87$ & 10 & 17 & 73 & A & 1,04 & 2,58 & 60 \\
\hline & & $\mathrm{BC}$ & $87-150$ & 32 & 16 & 52 & A & 1,02 & 2,57 & 60 \\
\hline & Andic & Ap & $0-13$ & 51 & 25 & 24 & FA a & 0,84 & 2,45 & 66 \\
\hline & Haplohumults & $\mathrm{AB}$ & $13-25$ & 66 & 5 & 29 & FA a & 0,94 & 2,70 & 65 \\
\hline & 44 & Bt1 & $25-57$ & 29 & 19 & 52 & A & 1,17 & 2,66 & 56 \\
\hline & & $\mathrm{Bt} 2$ & $57-104$ & 16 & 27 & 57 & A & 1,22 & 2,64 & 54 \\
\hline & & Bt3 & $104-130$ & 21 & 32 & 47 & A & 1,35 & 2,84 & 52 \\
\hline & & $\mathrm{BC}$ & $130-145$ & nd & nd & nd & nd & nd & nd & nd \\
\hline & Ustic & A & $0-17$ & 31 & 19 & 50 & A & nd & 2,00 & nd \\
\hline & Haplohumults & Bt1 & $17-40$ & 13 & 11 & 76 & A & nd & 2,40 & nd \\
\hline & 12 & Bt2 & $40-130$ & 11 & 23 & 66 & A & nd & 2,35 & nd \\
\hline & & $\mathrm{Bt} 3$ & $130-200$ & 13 & 29 & 58 & A & nd & 2,50 & nd \\
\hline
\end{tabular}


Cuadro 2. Características físicas de suelos desarrollados sobre superficies antiguas.

\begin{tabular}{|c|c|c|c|c|c|c|c|c|c|c|}
\hline \multirow{2}{*}{$\begin{array}{l}\text { Material } \\
\text { parental }\end{array}$} & \multirow{2}{*}{$\begin{array}{l}\text { Clasificación } \\
\text { taxonómica }\end{array}$} & \multirow[t]{2}{*}{ Horizonte } & \multirow[t]{2}{*}{ Prof. (cm) } & \multicolumn{3}{|c|}{ Textura (\%) } & \multirow{2}{*}{$\frac{\text { Clase }}{\text { textural }}$} & \multirow{2}{*}{$\frac{\mathrm{Mg} \cdot \mathrm{m}^{-3}}{\text { D. aparente }}$} & \multirow{2}{*}{$\frac{\mathrm{Mg} \cdot \mathrm{m}^{-3}}{\text { D. real }}$} & \multirow{2}{*}{$\frac{\%}{\text { Porosidad }}$} \\
\hline & & & & Arena & Limo & Arcilla & & & & \\
\hline \multirow{37}{*}{ 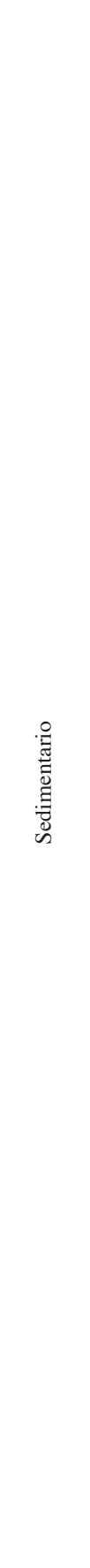 } & Andic & Ap & $0-18$ & 48 & 28 & 24 & FAa & 1,02 & 2,66 & 62 \\
\hline & Palehumults & $\mathrm{AB}$ & $18-28$ & 28 & 19 & 53 & A & 0,98 & 2,70 & 64 \\
\hline & \multirow[t]{3}{*}{38} & Btc1 & $28-46$ & 18 & 18 & 64 & A & 1,13 & 2,80 & 60 \\
\hline & & Bt2 & $46-90$ & 11 & 20 & 69 & A & 1,29 & 2,74 & 53 \\
\hline & & $\mathrm{Bt} 3$ & $90-120$ & nd & nd & nd & nd & nd & nd & nd \\
\hline & Andic & A & $0-22$ & 20 & 24 & 56 & A & nd & 2,10 & nd \\
\hline & Palehumults & Bt1 & $22-45$ & 19 & 17 & 64 & A & nd & 2,12 & nd \\
\hline & \multirow[t]{3}{*}{27} & Bt2 & $45-98$ & 11 & 27 & 62 & A & nd & 2,20 & nd \\
\hline & & Bt3 & $98-170$ & 13 & 21 & 66 & A & nd & 2,64 & nd \\
\hline & & $\mathrm{C}$ & $170-x x$ & 20 & 21 & 59 & A & nd & 2,20 & nd \\
\hline & Ustic & A & $0-20$ & 29 & 22 & 49 & A & nd & 2,07 & nd \\
\hline & Palehumults & Bt1 & $20-45$ & 13 & 16 & 71 & A & nd & 1,97 & nd \\
\hline & \multirow[t]{2}{*}{26} & $\mathrm{Bt} 2$ & $45-165$ & 7 & 22 & 71 & A & nd & 1,67 & nd \\
\hline & & $\mathrm{BC}$ & $165-\mathrm{xx}$ & 20 & 34 & 46 & A & nd & 2,08 & nd \\
\hline & Aquic & A & $0-26$ & 33 & 21 & 46 & A & nd & 2,16 & nd \\
\hline & Palehumults & Bt1 & $26-65$ & 13 & 13 & 74 & A & nd & 2,70 & nd \\
\hline & 20 & $\mathrm{Bt} 2$ & $65-185$ & 10 & 15 & 75 & A & nd & 2,30 & nd \\
\hline & Typic & Ap & $0-23$ & 13 & 28 & 59 & A & 0,96 & 2,20 & 56 \\
\hline & \multirow[t]{3}{*}{ Haplustults } & Bt1 & $23-59$ & 12 & 17 & 71 & A & 1,08 & 2,42 & 55 \\
\hline & & $\mathrm{Bt} 2$ & $59-95$ & 5 & 19 & 76 & A & 1,23 & 2,50 & 51 \\
\hline & & $\mathrm{BC}$ & $95-150$ & 13 & 27 & 60 & A & 1,15 & 2,50 & 54 \\
\hline & Aquic & Ap & $0-15$ & 40 & 15 & 45 & A & 1,01 & 2,50 & 60 \\
\hline & Haplustults & Bt1 & $15-45$ & 15 & 17 & 68 & A & 1,25 & 2,66 & 53 \\
\hline & \multirow[t]{3}{*}{40} & $\mathrm{Bt} 2$ & $45-66$ & 9 & 16 & 75 & A & 1,29 & 2,71 & 52 \\
\hline & & $\mathrm{Bt} 3$ & $66-123$ & 5 & 15 & 80 & A & 1,27 & 2,65 & 52 \\
\hline & & $\mathrm{BC}$ & $123-180$ & 5 & 17 & 78 & A & 1,31 & 2,59 & 49 \\
\hline & Typic & Ap & $0-10$ & 45 & 26 & 29 & FA a & 0,94 & 2,55 & 63 \\
\hline & Rhodustults & $\mathrm{AB}$ & $10-20$ & 42 & 20 & 38 & FA & 0,95 & 2,55 & 63 \\
\hline & \multirow[t]{2}{*}{41} & Bt1 & $20-70$ & 22 & 25 & 53 & A & 1,12 & 2,60 & 57 \\
\hline & & $\mathrm{BC}$ & $70-150$ & 35 & 30 & 35 & FA & 1,07 & 2,59 & 59 \\
\hline & Typic "Paralithic" & A & $0-18$ & 57 & 20 & 23 & FAa & nd & 2,20 & nd \\
\hline & Ustorthents & $\mathrm{C} 1$ & $18-82$ & 55 & 18 & 27 & FAa & nd & 2,49 & nd \\
\hline & 17 & $\mathrm{C} 2$ & $82-145$ & nd & nd & nd & nd & nd & nd & nd \\
\hline & Andic & A & $0-42$ & 42 & 36 & 22 & $\mathrm{~F}$ & nd & 1,73 & nd \\
\hline & Palehumults & Bt1 & $42-64$ & 10 & 18 & 72 & A & nd & 2,16 & nd \\
\hline & \multirow[t]{2}{*}{25} & $\mathrm{Bt} 2$ & $64-100$ & 6 & 14 & 80 & A & nd & 2,23 & nd \\
\hline & & $\mathrm{Bt} 3$ & $100-160$ & 4 & 20 & 76 & A & nd & 2,25 & nd \\
\hline
\end{tabular}


5. Densidad aparente (Da): Los Ultisoles tienen un ámbito de variación de la $\mathrm{Da}$ $\left(\mathrm{Mg} . \mathrm{m}^{-3}\right)$ que tiende a aumentar con la profundidad (Cuadro 2). Todos los horizontes estudiados, tienen valores de 0,62 a 1,35 Mg.m $\mathrm{m}^{-3}$, con promedios en horizontes $\mathrm{A}$ de $0,95 \mathrm{y}$ en el horizonte $\mathrm{B}$ de 1,15 , lo que los ubica dentro del ámbito reportado para suelos de Costa Rica por Alvarado y Forsythe (2005). En superficie la Da tiende a ser menor debido al mayor contenido de materia orgánica y en algunas ocasiones, por propiedades ándicas, mientras que en el subsuelo la Da aumenta por el enriquecimiento de arcilla iluviada en el horizonte argílico. Este horizonte con acumulo de arcilla, se encuentra a cierta profundidad del perfil de suelo a menos que haya sido erosionado y esté expuesto (Soil Survey Staff 1999). La Da de 0,62 a 0,99 Mg.m ${ }^{-3}$ del horizonte A se atribuye a la materia orgánica, materiales parentales de cenizas volcánicas y presencia de compuestos órgano-minerales de los subgrupos Andic y del suborden Humults. Los valores más altos de $\mathrm{Da}\left(0,90\right.$ a 1,32 $\left.\mathrm{Mg} \cdot \mathrm{m}^{-3}\right)$ se encontraron en los suelos sobre materiales coluviales y los valores intermedios en suelos derivados de materiales sedimentarios $(0,74$ a $1,06 \mathrm{Mg} \cdot \mathrm{m}^{-3}$ ). En general, la Da del horizonte $\mathrm{B}$ es mayor que la encontrada en el horizontes A y tiende a aumentar al profundizar el perfil (Figura 3). Algunos horizontes argílicos presentan un valor ligeramente inferior que 1,0 probablemente debido a un mayor contenido de materia orgánica cerca de la superficie, que redunda en mayor actividad biológica, mayor contenido de raíces y valores de densidad más baja a la que ocurre en los intervalos de mayor profundidad. Se encontró una relación exponencial negativa entre la Da y la porosidad (Figura 4).

6. Densidad real o de partículas (Dp): Comúnmente se asume una Dp para suelos
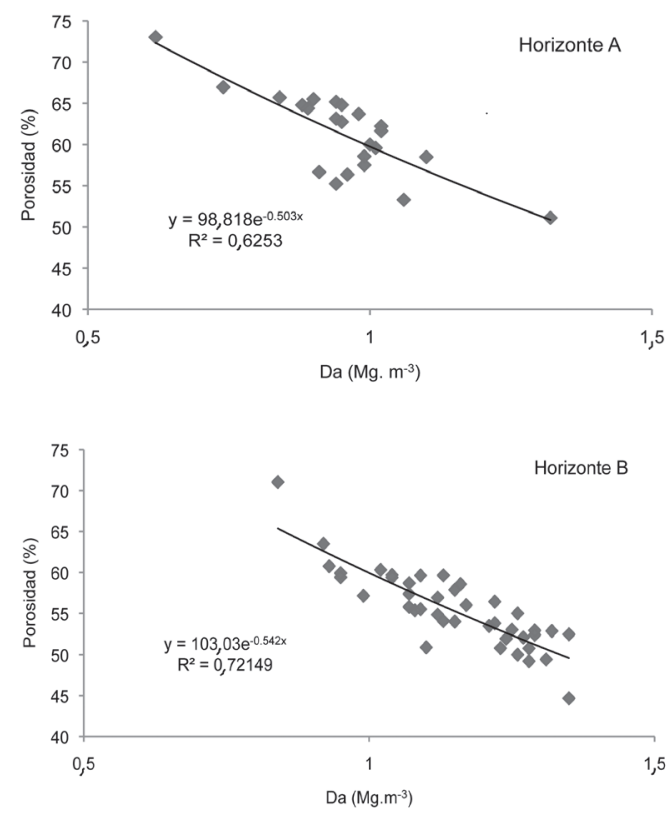

Fig. 4. Relación entre la Da y la porocidad en Ultisoles desarrollados sobre superficies geológicas antiguas.

minerales de 2,65 Mg.m ${ }^{-3}$ y para el humus de 1,37 Mg.m $\mathrm{m}^{-3}$ (Porta et al. 1994). Debido a que la $\mathrm{Dp}$ de todos los horizontes osciló entre 2,0 y 2,8 Mg.m ${ }^{-3}$ (Cuadro 2), se podría asumir que en los Ultisoles fuertemente meteorizados, domina la Dp de la fracción mineral del suelo, mientras que los valores más bajos se pueden asociar a un mayor contenido de materia orgánica cerca de la superficie.

7. Porosidad: El porcentaje total de poros de la superficie es ligeramente mayor que el del subsuelo, variando de 51 a $73 \%$ en el horizonte A y entre 44 y $71 \%$ en el horizonte B (Cuadro 2). Los promedios de porosidad de los suelos desarrollados sobre los diferentes materiales parentales, varían de 59,5 a 61,8\% para el horizonte A y de 54,9 y 58,8\% en el horizonte B (Figura 5). Esto se atribuye a que la microporosidad del horizonte 


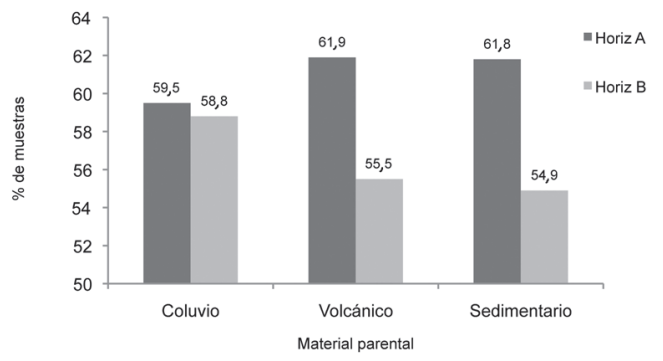

Fig. 5. Porosidad (\%) en horizontes A y B de Ultisoles sobre diferente material parental.

$\mathrm{B}$, contribuye con una cantidad de poros menor que la macro porosidad de los horizontes A. El mayor porcentaje de poros en la superficie se debe al mayor contenido de materia orgánica, mayor actividad biológica, mayor contenido de raíces y valores de Da más bajos a los que ocurren en los intervalos a mayor profundidad.

\section{Reacción del suelo (pH en $\mathrm{H}_{2} \mathrm{O}, \mathrm{KCL}$}

y NaF): No se observa una diferencia importante en los datos de $\mathrm{pH}$ obtenidos en Ultisoles desarrollados sobre los diferentes materiales parentales (Cuadro 3). En general, la reacción del suelo es ácida en todos los suelos analizados, con excepción del perfil 26 que presenta valores de $\mathrm{pH}$ de 6,0 a 7,1. En el horizonte A se obtuvo un mínimo de 4,1 en Ultisoles de origen coluvial (Perfil 45 Aquic Haplohumults), un máximo de 6,1 sobre material de origen sedimentario (Perfil 26 Ustic Haplohumults), con un promedio general de 4,9. En suelos derivados de material sedimentario, el horizonte Bt3 del perfil 1 (Andic Haplohumults) presentó un $\mathrm{pH} 4,0$ y el valor máximo de pH 6,9; en el horizonte Bt2 del perfil 26 (Ustic Haplohumults), el pH promedio en el subsuelo es de 5,4. Los perfiles que tienen $\mathrm{pH}$ en $\mathrm{KCl}$, tienen la misma tendencia que el $\mathrm{pH}$ en agua, solo que con valores aproximadamente menores en una unidad. El valor de $\mathrm{pH}$ en $\mathrm{NaF}$ osciló entre 8,2 y 11,2 en el horizonte A y de 9,1 a 10,0 en el horizonte $\mathrm{B}$, lo que confirma la presencia de materiales parentales de origen volcánico, tanto en superficie como en el subsuelo.

9. Capacidad de intercambio de cationes (CIC): Los Ultisoles bajo estudio (Cuadro 3) presentan una CIC media y alta. Sin considerar el horizonte genético $\mathrm{Bt}$, la CIC de suelo promedio más baja se encontró en los coluvios ( $25 \mathrm{cmol}(+)$. $\left.\mathrm{kg}^{-1}\right)$, seguida de los suelos sobre el sedimentario (39 cmol(+). $\left.\mathrm{kg}^{-1}\right)$ y en los volcánicos $(41 \mathrm{cmol}(+)$. $\left.\mathrm{kg}^{-1}\right)$. En general, la CIC media en la superficie es de $35 \mathrm{cmol}(+) \cdot \mathrm{kg}^{-1}$, mientras que en el subsuelo alcanza los $29 \mathrm{cmol}(+) \cdot \mathrm{kg}^{-1}$. Los mayores valores de CIC $(71,5)$ se registran en el horizonte A de un Andic Haplohumults (perfil 6) desarrollado sobre sedimentario con deposición de cenizas volcánicas y los menores $\left(17,82 \mathrm{cmol}(+) \cdot \mathrm{kg}^{-1}\right)$ en un Typic "Aquic" Paleustults (perfil 21) desarrollado sobre coluvios. Esta variabilidad se atribuye al tipo de arcilla, materia orgánica, óxidos de hierro, aluminio y por la presencia de propiedades ándicas en muchos de los perfiles. Se encontraron relaciones lineales negativas entre la CIC y el contenido de arcilla en los suelos desarrollados sobre coluvios $\left(\mathrm{R}^{2}=0,8006\right)$ y materiales sedimentarios $\left(\mathrm{R}^{2}=0,5903\right)$. No hay relación de ningún tipo entre estas mismas variables en los suelos desarrollados sobre material volcánico, lo que parece deberse a una alta variabilidad en la mineralogía de la fracción fina de estos suelos. En la Figura 6 se observa que con porcentajes mayores de arcilla, la CIC de los suelos es menor, lo que se considera ocurre por una diferente composición mineralógica, donde los coloides exhiben un avanzado estado de meteorización.

10. Cationes intercambiables: En los Ultisoles se encontró una suma de bases baja, atribuible a un material parental bajo en minerales meteorizables, pequeñas cantidades de minerales alterables y lavado de bases (Cuadro 3). Indiferente del horizonte y del material parental, el rango de variabilidad es amplio y varía de 


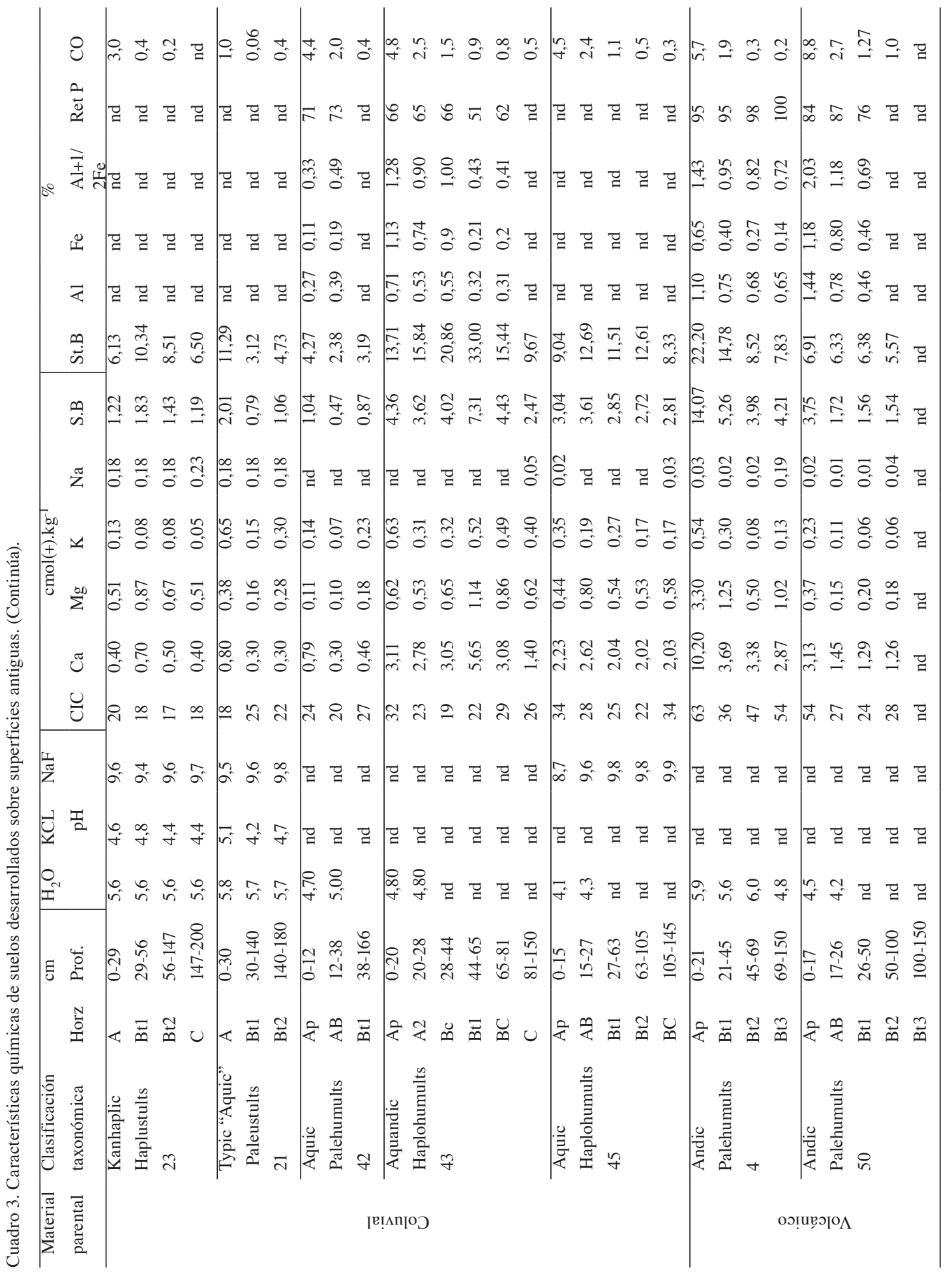




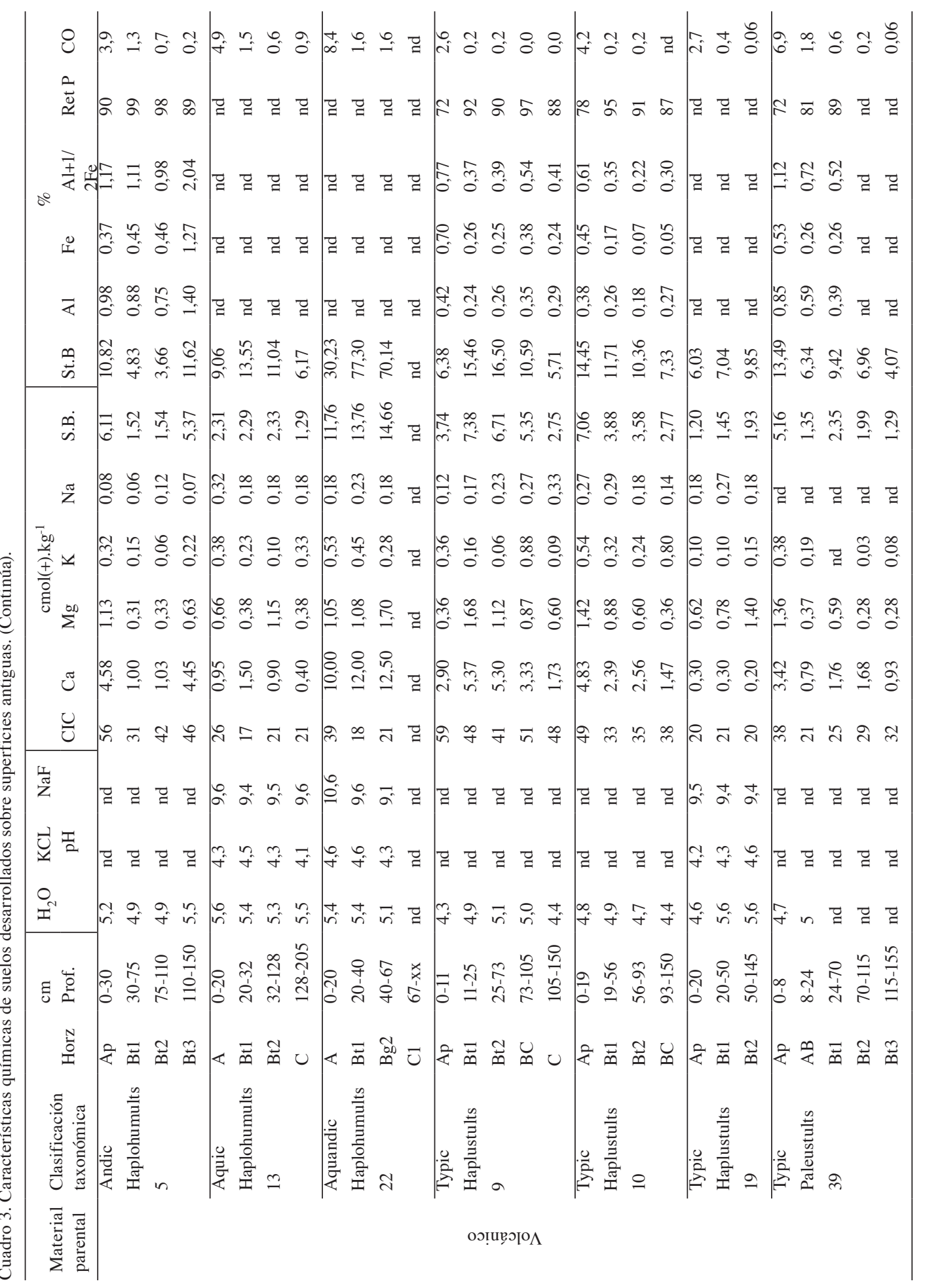




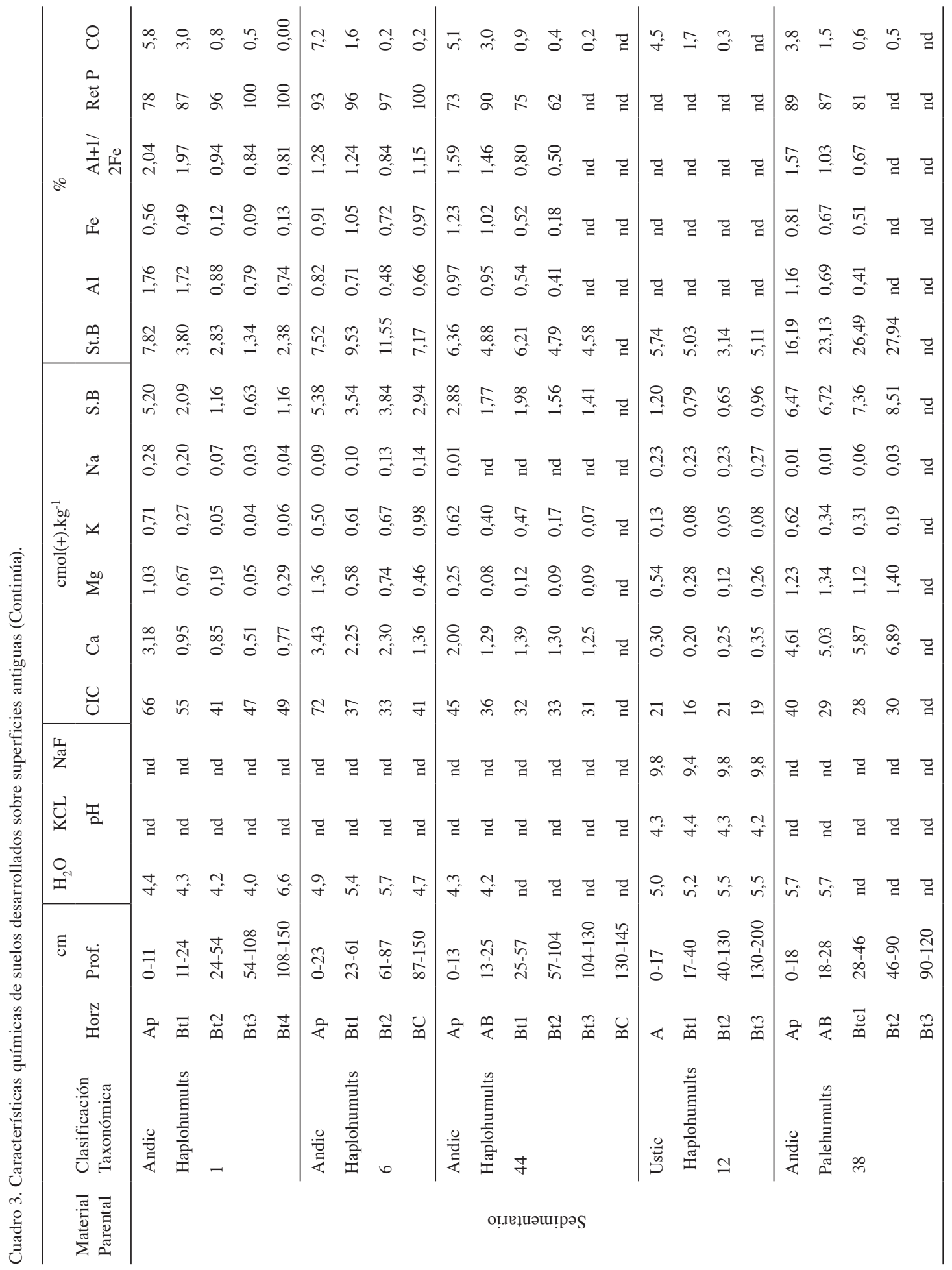




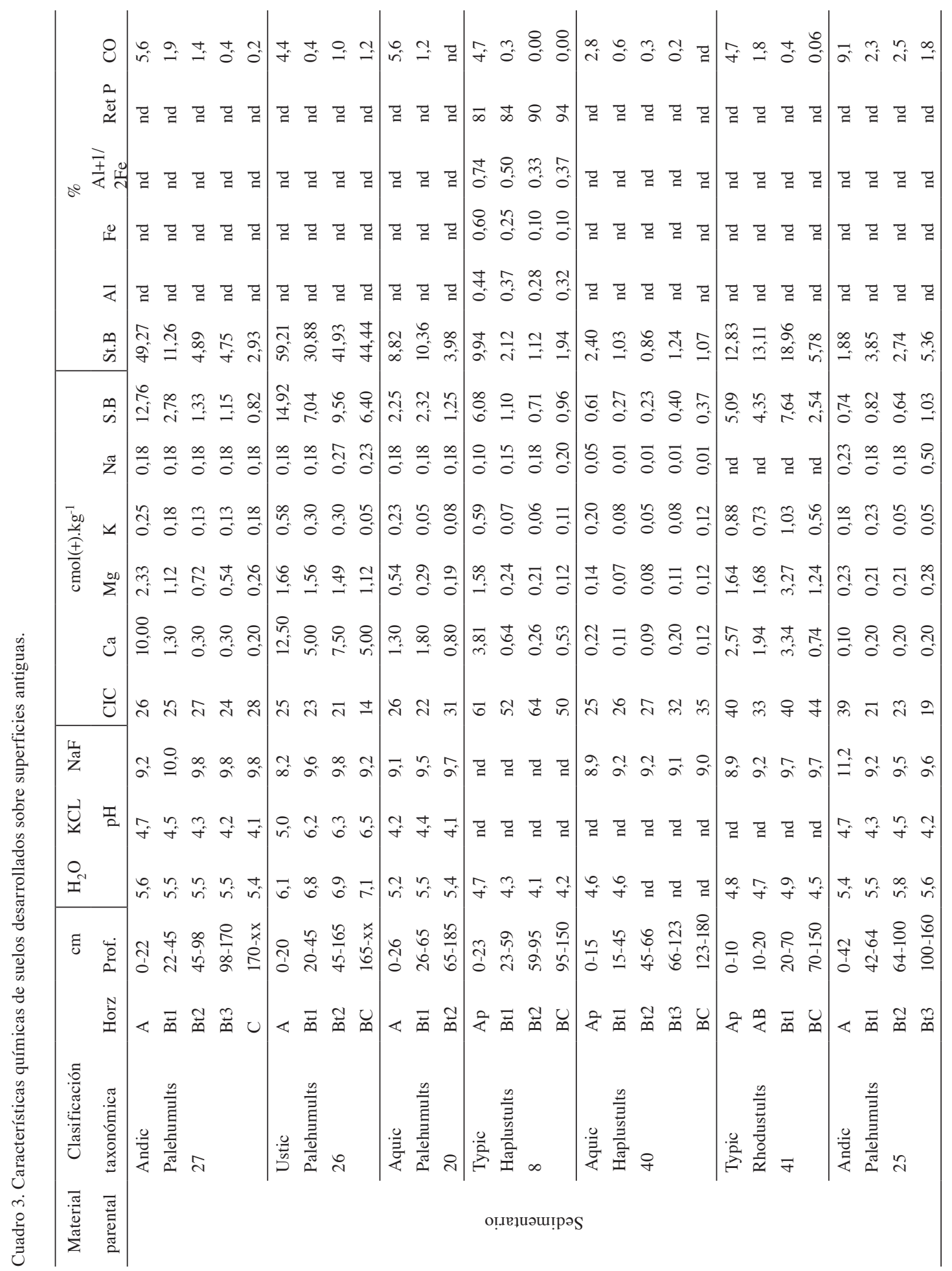



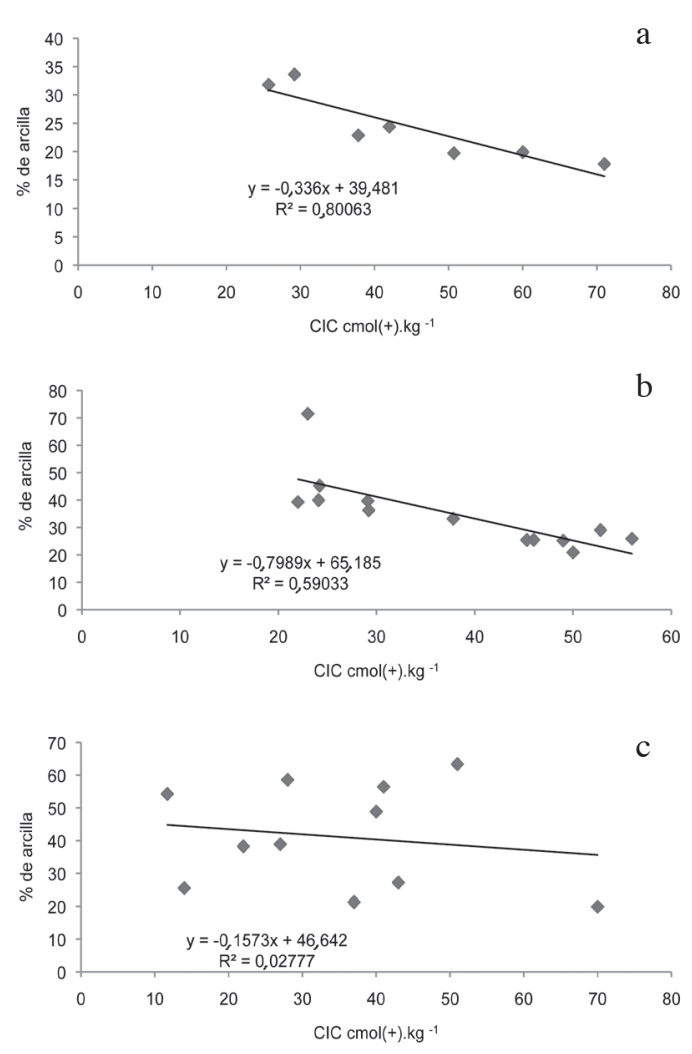

Fig. 6. Efecto del porcentaje de arcilla en la CIC (cmol(+). kg-1) en suelos desarrollados a partir de (a)material coluvial, (b)sedimentario y (c )volcánico.

$14,92 \mathrm{cmol}(+) \cdot \mathrm{kg}^{-1}$ de suelo en el horizonte A del perfil 27 (Andic Palehumults) a $0,23 \mathrm{cmol}(+) \cdot \mathrm{kg}^{-1}$ en el horizonte Bt 2 del perfil 40. En general los suelos sobre coluvios tienen valores menores a $4,4 \mathrm{cmol}(+) \cdot \mathrm{kg}^{-1}$ y de estos, solo en el horizonte Bt del perfil 43 (Aquandic Haplohumults) tiene 7,31 cmol(+). $\mathrm{kg}^{-1}$, como resultado del acúmulo de bases lixiviadas desde la superficie. En estos suelos, el valor más bajo de 0,47 se encontró a $12 \mathrm{~cm}$ de profundidad, en el horizonte $\mathrm{AB}$ de un Aquic Palehumults. En relación con los suelos ubicados sobre material volcánico, la mayoría poseen suma de bases menor a 7,0. Valores mayores a 10 y menores a 15 se hallaron únicamente en el horizonte A del perfil 9 (Andic Palehumults) y en todo el perfil 22. Con algunas excepciones, los suelos localizados sobre superficies sedimentarias, presentan una suma de bases menor a 4. Un pequeño número de muestras oscilan entre 5 y 9. Los valores máximos de 12 y 14 se encontraron en los horizontes A de los perfiles 26 y 27 (Andic y Ustic Palehumults). El valor mínimo de estos suelos es de 0,23 y se encontró en el horizonte Bt2 del perfil 40 (Aquic Haplohumults). Aunque los datos de cationes intercambiables parecen bajos, los mismos se consideran válidos, ya que en su gran mayoría fueron hechos en los laboratorios del Centro de Investigaciones Agronómicas de la Universidad de Costa Rica, por metodologías certificadas internacionalmente.

\section{Porcentaje de retención de fósforo:}

Las reacciones de fijación de fósforo son elevadas en casi todos los suelos estudiados (Cuadro 3). Indiferente del horizonte y del material parental, existen valores promedios de fósforo adsorbido cercanos a $78 \%$, con mínimos de $50 \%$ y valores de retención de hasta $100 \%$. Para los Ultisoles estudiados, esto se atribuye a que los fosfatos tienen alta afinidad con el $\mathrm{Al}$ y el Fe presentes, con los que forman precipitados insolubles. En suelos con propiedades ándicas, la retención se atribuye a minerales como la alófana, imogolita y a complejos humus-aluminio.

\section{CONCLUSIONES}

Los Ultisoles son el orden de suelos que ocupa la mayor superficie del área estudiada de la subcuenca (9289 ha, 38\%). Están distribuidos en 16 unidades cartográficas, 14 asociaciones y 2 consociaciones (Cuadro 4). Con los Ultisoles coexisten Inceptisoles y Entisoles que ocupan áreas menores; los Inceptisoles se presentan principalmente en la unidad volcánica Grifo Alto.

Los Ultisoles se formaron a partir de materiales parentales del Pleistoceno o más antiguos y en relieves ondulados a fuertemente ondulados. Dos subórdenes fueron reconocidos: Humults y Ustults. Los Humults tienen cantidades mayores de materia orgánica. A nivel de subgrupo se encontraron Haplustults, Paleustults, 
Cuadro 4. Unidades cartográficas y clasificación de Ultisoles en la subcuenca media y alta.

\begin{tabular}{|c|c|c|c|c|}
\hline Unidad Cartográfica & Símbolo & Unidad Taxonómica & ha & $\%$ \\
\hline Asociación Vara Blanca & VB & $\begin{array}{l}\text { Typic Haplustults, arcillosa fina, isotérmico; Aquic } \\
\text { Haplohumults; arcillosa muy fina, Isotérmico }\end{array}$ & 428,23 & 1,75 \\
\hline Asociación San Pedro & SP & $\begin{array}{l}\text { Andic Palehumults, arcillosa muy fina, isotérmico; } \\
\text { Typic Haplustults, arcillosa muy fina, isotérmico. }\end{array}$ & 561,89 & 2,29 \\
\hline $\begin{array}{l}\text { Asociación La } \\
\text { Virgen-Abejonal }\end{array}$ & $\mathrm{Vi}-\mathrm{Ab}$ & $\begin{array}{l}\text { Andic Palehumults, arcillosa muy fina, isomésico; } \\
\text { Andic Dystrustepts, francosa fina, isomésico. }\end{array}$ & 462,98 & 1,89 \\
\hline $\begin{array}{l}\text { Consociación La } \\
\text { Cachimba }\end{array}$ & Cach & Andic Haplohumults, arcillosa muy fina, isotérmico & 164,87 & 0,67 \\
\hline Asociación Carrizales & Car & $\begin{array}{l}\text { Typic Paleustults, arcillosa fina, isotérmico; Typic } \\
\text { Haplustults, arcillosa fina, isotérmico }\end{array}$ & 564,42 & 2,30 \\
\hline Asociación San Isidro & SI & $\begin{array}{l}\text { Typic Haplustults, arcillosa fina, isotérmico; Typic } \\
\text { Paleustults; arcillosa fina, Isotérmico }\end{array}$ & 1334,93 & 5,44 \\
\hline Asociación Llano Bonito & Llabo & $\begin{array}{l}\text { Typic Haplustults, arcillosa muy fino, isotérmico; } \\
\text { Typic Ustorthents, francosa fina, isotérmico }\end{array}$ & 1296,38 & 5,28 \\
\hline $\begin{array}{l}\text { Asociación Higueronal - } \\
\text { La Bandera }\end{array}$ & $\mathrm{Hi}-\mathrm{Ba}$ & $\begin{array}{l}\text { Andic Haplohumults, arcillosa muy fina, isotérmico; } \\
\text { Andic Palehumults, arcillosa muy fina, isotérmico }\end{array}$ & $1.128,62$ & 4,60 \\
\hline $\begin{array}{l}\text { Asociación Llano La } \\
\text { Piedra - El Vapor }\end{array}$ & Lla-Va & $\begin{array}{l}\text { Andic Palehumults, arcillosa muy fina, isotérmico; } \\
\text { Ustic Haplohumults, arcillosa muy fina, isotérmico. }\end{array}$ & 357,69 & 1,46 \\
\hline $\begin{array}{l}\text { Asociación Guadalupe- } \\
\text { La Pastora }\end{array}$ & Gua-Pa & $\begin{array}{l}\text { Andic Palehumults, arcillosa fina, isotérmica; Typic } \\
\text { Rhodustults, arcillosa fina, kaolinítica con mala } \\
\text { cristalización, isotérmica }\end{array}$ & 1334,66 & 5,44 \\
\hline $\begin{array}{l}\text { Asociación Zapotal - La } \\
\text { Esperanza }\end{array}$ & Za-Es & $\begin{array}{l}\text { Aquic Haplustults arcillosa muy fina, isotérmico; Typic } \\
\text { "Aquic" Paleustults, arcillosa muy fina, isotérmica }\end{array}$ & 942,26 & 3,84 \\
\hline $\begin{array}{l}\text { Asociación Mata de } \\
\text { Caña }\end{array}$ & $\mathrm{MC}$ & $\begin{array}{l}\text { Andic Haplohumults, arcillosa fina, kaolinítica con } \\
\text { mala cristalizacion, isotérmica; Aquic Palehumults, } \\
\text { arcillosa muy fina, isotérmico }\end{array}$ & 742,4 & 3,03 \\
\hline Consociación San Carlos & $\mathrm{SC}$ & Andic Haplohumults, arcilloso muy fino, isotérmico & 328,03 & 1,34 \\
\hline Asociación San Lorenzo & SL & $\begin{array}{l}\text { Ustic Haplohumults, arcillosa fina, kaolinítica, } \\
\text { isotérmica }\end{array}$ & 414,05 & 1,69 \\
\hline Asociación San Marcos & SM & $\begin{array}{l}\text { Aquic Palehumults, arcillosa fina, kaolinítica, } \\
\text { isotérmico; Kanhaplic Haplustults, arcillosa muy fina, } \\
\text { isotérmico }\end{array}$ & 1060,98 & 4,32 \\
\hline Asociación El Balar & Bal & $\begin{array}{l}\text { Aquandic Haplohumults, arcillosa fina, kaolinítica, } \\
\text { isotérmica; Aquic Palehumults, arcillosa fina, } \\
\text { kaolinítica, isotérmica }\end{array}$ & 251,21 & 1,02 \\
\hline
\end{tabular}


Haplohumults, Palehumults, Rhodustults. Los subgrupos clasificados son Typic Haplustults, Aquic Haplustults, Typic Paleustults, Andic Haplohumults, Aquic Haplohumults, Aquandic Haplohumults, Ustic Haplohumults, Andic Palehumults, Typic Rhodustults.

Los subgrupos Andic Haplohumults, Aquandic Haplohumults, Andic Palehumults presentan en los horizontes superficiales, deposiciones de cenizas volcánicas de edad cercana a los 700 años, sin conocerse a ciencia cierta la proveniencia de las cenizas. Ejemplos de procesos pedogenéticos que han inferido en las características de Ultisoles en la subcuenca del río Pirrís se presentan en el Cuadro 5.

A nivel de familia, la clasificación por textura es arcillosa y arcillosa muy fina, la mineralógica es caolinítica mal cristalizada (Cuadro 4).

La morfología típica ha sido dominada por horizontes de arcillas iluviadas. Los contenidos de arcilla incrementan desde el horizonte A hasta el B y tener un decrecimiento en el horizonte C.

Los Ultisoles son los suelos de más alta evolución encontrados. Dominan la parte media de la subcuenca y se encuentran tanto sobre litologías del Pleistoceno al Oligoceno coluviales, volcánicas como sedimentarias. Tienen fertilidad baja a muy baja, son ácidos, arcillosos, con alta fijación de fósforo y un drenaje interno lento que favorece la escorrentía superficial y la erosión.

En el área estudiada, los Ultisoles se formaron en litologías con granulometría fina a mediana y a partir de minerales meteorizables que favorecen la formación de arcilla. Estos suelos se encuentran sobre litologías volcánicas (lavas basálticas, andesíticas, andesitas basálticas) y sedimentarias (lutitas, areniscas de grano fino a medio). Las rocas sedimentarias (lutitas, areniscas de grano fino a medio) son de origen marino y su edad es el Oligoceno a Mioceno Inferior (34 a $23 \mathrm{Ma}$ ). Las rocas volcánicas pertenecen al Plioceno (5,5 -1,9 Ma), químicamente son intermedias en cuanto al contenido de sílice (cuarzo) y mineralógicamente exhiben olivinos, piroxenos, feldespatos, plagioclasas cálcicas (rocas basálticas) a plagioclasas de carácter intermedio a sódicas (andesitas). Ha sido definida la influencia del material parental en los horizontes inferiores y de la materia orgánica y cenizas

Cuadro 5. Ejemplos de procesos, propiedades y características de algunos Ultisoles.

\begin{tabular}{|c|c|c|c|}
\hline Orden & Suborden & Gran Grupo & Subgrupo \\
\hline 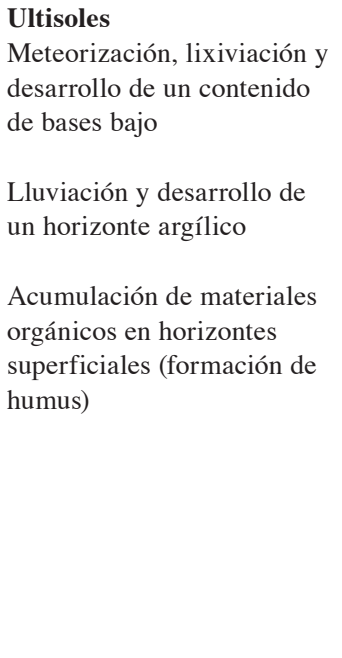 & $\begin{array}{l}\text { Ustults: } \\
\text { Clase régimen de humedad } \\
\text { en el perfil de suelo } \\
\text { Humults: } \\
\text { Acumulación de materia } \\
\text { orgánica }\end{array}$ & $\begin{array}{l}\text { Paleustults: } \\
\text { Con el incremento de la } \\
\text { profundidad del suelo, no } \\
\text { disminuye el contenido de } \\
\text { arcilla en un } 20 \% \\
\text { Haplohumults: } \\
\text { Con un mínimo número } \\
\text { horizontes necesarios } \\
\text { para formar parte de un } \\
\text { determinado taxón } \\
\text { Rhodustults: } \\
\text { Desarrollo de colores rojos } \\
\text { oscuros en suelos con } \\
\text { drenaje libre y contenidos } \\
\text { apreciables de óxidos de } \\
\text { hierro }\end{array}$ & $\begin{array}{l}\text { Andic Haplohumults: } \\
\text { Densidades aparentes de } 1,0 \\
\mathrm{~g} / \mathrm{cm}^{3} \text { o menos y porcentaje } \\
\text { de aluminio mas la mitad } \\
\text { del hierro, medidas en } \\
\text { oxalatos de amonio en } 18 \mathrm{~cm} \\
\text { dentro de los primeros } 75 \\
\text { cm de la superficie el suelo } \\
\text { mineral } \\
\text { Ustic Haplohumults: } \\
\text { Con régimen de humedad } \\
\text { ústico }\end{array}$ \\
\hline
\end{tabular}


volcánicas en los superiores. Las densidades aparentes son más bajas en el horizonte A que las del subsuelo. La densidad de partículas también es más baja en los horizontes A, consecuencia de un mayor contenido de humus y es más alta en el subsuelo, como efecto del material de partida.

En cuanto al régimen de humedad, todos los Ultisoles presentan un régimen ústico y en general su régimen de temperatura es isotérmico, con excepción de la unidad cartográfica La Virgen-Abejonal donde es isomésico. El clima ha actuado en el área como factor formador de Ultisoles a través de la precipitación y la temperatura. La abundancia de agua y temperaturas elevadas han provocado una fuerte hidrólisis, con alteración de minerales y colapso de sus estructuras. Los óxidos de silicio se lixivian, mientras que el aluminio y el hierro se combinan con el oxigeno y se mantienen en el suelo. Con la ganancia de aluminio y hierro en el suelo se produce la laterización, lixiviación de bases, acumulo de óxidos de hierro, aluminio y aumento de la acidez de los suelos.

Los principales tipos de relieve donde se presentan los Ultisoles son de origen tectónico erosivo y de sedimentación. La fisiografía la caracterizan laderas del Terciario (Cordillera de Talamanca y Fila Brunqueña) y terrazas medias en piedemonte relacionadas con la tectónica de alzamiento de Talamanca (sedimentos coluviales). El relieve ha favorecido los procesos de erosión superficial y de remoción en masa en diferente magnitud. Junto con el clima y la geología han moldeado las geoformas presentes en las superficies ocupadas por Ultisoles.

La edad geológica de las superficies sobre las que se han desarrollado los Ultisoles son concordantes con Wilding et al. (1983) y son a partir del Pleistoceno o más antiguos. Sin embargo, edades de suelos Ultisoles de los abanicos aluviales coalescentes del pie de monte de la Cordillera de Talamanca (900-1000 msnm), tienen una edad estimada con 14C de 45000 años a más de 65000 años (Kesel y Spicer 1985).

La actividad humana, asociada en ocasiones con eventos climáticos extremos, ha causado una disposición y concentración inadecuada de aguas superficiales, manifiesta en un proceso erosivo (erosión superficial y movimientos en masa) que se ha desarrollado gradualmente. Algunos factores que contribuyen con los procesos de degradación de los Ultisoles son los movimientos telúricos, los caminos de finca mal diseñados, ausencia de superficie de rodamiento, inadecuados manejos de agua, texturas finas y muy finas, drenaje interno de suelo lento y a ello se le debe sumar la presencia de infraestructura que con sus construcciones eliminan la cobertura vegetal.

\section{LITERATURA CITADA}

ALVARADO A., FORSYTHE W. 2005. Variación de la densidad aparente en órdenes de suelos de Costa Rica. Agronomía Costarricense 29(1):85-94.

ALVARADO A., GLOBER N., OBANDO O. 1982. Reconocimiento de suelos de Puriscal-Salitrales y Tabarcia-San Ignacio de Acosta, pp. 102-118. In: El componente arbóreo en Acosta y Puriscal, Costa Rica. ASCONA/CATIE/GTZ/MAG.

BERGOEING J.P. 2007. Geomorfología de Costa Rica. 2 ed. Librería Francesa. 328 p.

BLASER J., CAMACHO M. 1991. Estructura, composición y aspectos silviculturales de un bosque de robles (Quercus spp.) del piso montano en Costa Rica. Proyecto CATIE/COSUDE, Colección Silvicultura t Manejo de Bosques Naturales $N^{\circ} 1$. Turrialba, Costa Rica. 68 p.

BUOL S.W., HOLE F.D., McCRAKEN R.J. 1989. Soil genesis and classification. $3^{\text {rd }}$ ed. Iowa State University Press, Ames. USA. 446 p.

CHINCHILlA M., ALVARADO A., MATA R. 2011. Factores formadores y distribución de suelos de la subcuenca del río Pirrís, Talamanca, Costa Rica. Agronomía Costarricense. 35(1):33-57.

CUBERO D.A. 2002. Estudio semidetallado de suelos y clasificación de tierras de la cuenca del río Savegre. MAG, Dpto. Evaluación de Suelos y Tierras. San José, Costa Rica. 61 p.

DRIESE S.G., ORVIS K.H., HORN S.P., LI Z., JENNINGS D.S. 2007. Paleosol evidence for Quaternary uplift and the climate and ecosystem changes 
in the Cordillera de Talamanca, Costa Rica. Paleogeography, Paleoclimatology, Paleoecology 248:1-23.

GÓMEZ O., CHINCHILLA M. 2005. Estudio taxonómico y mineralógico de los suelos de la cuenca del río Térraba. MAG/ICE. San José, Costa Rica. 233 p.

HARRIS S.A. 1971a. Podsol development on volcanic ash deposits in the Talamanca range, Costa Rica, pp. 191209. In: Paleopedology: origin, nature and dating of paleosols. Halsted Press. New York, USA.

HARRIS S.A. 1971b. Quaternary vulcanicity in the Talamanca range of Costa Rica. Canadian Geographer 15(2):141-145.

HOLDRIDGE L.R., GRENKE W.C., HATHEWAY W.H., LIANG T., TOSI J. 1971. Forest environments in tropical life zones: a pilot study. New York, USA. $747 \mathrm{p}$.

ICAFE (Instituto del Café de Costa Rica), CIA (Centro de Investigaciones Agronómicas). 2000. Caracterización de suelos cafetaleros en la región de los Santos. En prensa.

ICE (Instituto Costarricense de Electricidad). 2007. Estudio de amenazas naturales y antrópicas en la cuenca del Río Pirrís. San José, CR, UEN PSA. 83 p.

KAPPELLE M., van UFFELEN J.G. 2005. Los suelos de los páramos de Costa Rica, pp. 147-159. In: Páramos de Costa Rica. Instituto nacional de Biodiversidad. Santo Domingo de Heredia, Costa Rica.

KESEL R.H., SPICER B.E. 1985. Geomorphological relationships and ages of soils on alluvial fans in the río General valley, Costa Rica. Catena 12:149-166.

LANDAETA A. 1977. Caracterización de la fracción mineral y determinación del ZPC de una catena de suelos derivados de cenizas volcánicas de la cordillera de Talamanca. Tesis de licenciatura, Universidad de Costa Rica, San José, Costa Rica. 90 p.

LANDAETA A., LÓPEZ C.A., ALVARADO A. 1978. Caracterización de la fracción mineral de suelos derivados de cenizas volcánicas de la Cordillera de Talamanca, Costa Rica. Agronomía Costarricense 2(2):117-129.

LÓPEZ H. 1978. Caracterización de la fracción mineral de cinco Andepts de los cantones de Corredores y Coto Brus. Tesis de licenciatura, Universidad de Costa Rica, San José, Costa Rica. 51 p.
MACIAS M.V. 1969. Propiedades morfológicas, físicas, químicas y clasificación de ocho latosoles de Costa Rica. Tesis de maestría, IICA, Turrialba, Costa Rica. $191 \mathrm{p}$.

MARTINI J., MACÍAS M. 1974. A study of six "latosols" from Costa Rica to elucidate the problems of classification, productivity and management of tropical soils. Soil. Sci. Soc. Amer. Proc. 38:644652.

MATA R. 1991. Los órdenes de suelos en Costa Rica, pp. 28-32. In: W.G. Vahrson, M. Alfaro y G. Palacios (eds.). Memoria Taller de Erosión de Suelos. UNA. Heredia.

MATA R., RAMÍREZ J.E. 1999. Estudio de caracterización de suelos y su relación con el manejo del cultivo de café en la Provincia de Heredia. ICAFE. San José, Costa Rica. 92 p.

OTÁROLA C.E., ALVARADO A. 1977. Caracterización y clasificación de algunos suelos del Cerro de la Muerte, Talamanca, Costa Rica. Suelos Ecuatoriales 8(1):397-400.

PELT E., CHABEAUX F., INNOCENT C., NAVARRE A.K., SAK P.B., BRANTLEY S.L. 2008. Uraniumthorium chronometry of weathering rinds: rock alteration rate and paleo-isotopic record of weathering fluids. Earth and Planetary Science Letters 276:98-105.

PORTA J., LOPEZ-ACEVEDO M., ROQUERO C. 1994 Edafología para la agricultura y el medio ambiente. Ediciones Mundi-Prensa. España. 807 p.

SANCHO F., NÚÑEZ J. 1985. Estudio de suelos. Secciones I y II de la Cuenca del Río Parrita. San José, CR, UCR. 167 p.

SOIL SURVEY STAFF. 2006. Soil Taxonomy: A basic system of soil classification for making and interpreting soil surveys. Tenth ed. Washington DC, USDA. 341 p.

SOLÓRZANO J.A. 1997. Evaluación de enmiendas orgánicas en el cultivo de la mora silvestre cv Vino (Rubus praecipuus) Bailey, en la Cima de Dota, San José, Costa Rica. Tesis de licenciatura, Universidad de Costa Rica, San José, Costa Rica. 107 p.

USDA-NRCS (National Soil Survey Center; Natural Resource Conservation Service; US Department of Agriculture). 2002. Field book for describing and sampling soils. Lincoln, Nebraska, USA. s.p. 
van UFFELEN J.G. 1991. A gelogical, geomorphological and soil transect study of the Chirripó massif and adjacent areas, Cordillera de Talamanca, Costa Rica. Tesis de maestría, Wageningen University, Wageningen. $72 \mathrm{p}$.

WILDING L.P., SMECK N.E., HALL G.F. 1983. Pedogenesis and soil taxonomy. Elsevier Science Publishers B V. Netherlands. 399 p.
WINOWIECKI 1. 2008. Soil biochemical patterns in the Talamanca foothills, Costa Rica: local knowledge and implications for agroecosystems. Ph.D. Thesis. University of Idaho/Centro Agronómico Tropical de Investigación y Enseñanza. USA. 172 p. 
